\title{
Simultaneous Two-Color Visualization of Lipid Droplets and Endoplasmic Reticulum and Their Interplay by Single Fluorescent Probes in Lambda Mode
}

\author{
Lifang Guo, ${ }^{\dagger, \S, \dagger}$ Minggang Tian, ${ }^{\dagger}$ Zhiyun Zhang, ${ }^{\S}$ Qing Lu,${ }^{\dagger}$ Zhiqiang Liu, ${ }^{\dagger}$ Guangle Niu, $,{ }^{*},+$, \\ Xiaoqiang $\mathrm{Yu}^{*, \dagger, \dagger}$
}
†State Key Laboratory of Crystal Materials, and Advanced Medical Research Institute, Shandong University. Jinan 250100, P. R. China.
E-mail: niugl@sdu.edu.cn; yuxq@sdu.edu.cn

${ }^{\S}$ Key Laboratory for Advanced Materials and Joint International Research Laboratory of Precision Chemistry and Molecular Engineering, Feringa Nobel Prize Scientist Joint Research Center, East China University of Science \& Technology, Shanghai 200237, P. R. China

${ }^{\ddagger}$ Shenzhen Research Institute of Shandong University, Shenzhen 518057, P. R. China. 


\section{Synthesis routes}

Scheme S1. The synthesis routes to PPC, EPC, MNC, and PC.<smiles>O=Cc1ccc(N(c2ccccc2)c2ccccc2)cc1</smiles><smiles>CCN(CC)c1ccc(C=O)cc1</smiles><smiles>CCN(CC)c1ccc(/C=C/C(=O)c2ccccc2O)cc1</smiles><smiles>CCN(CC)c1ccc(-c2oc3ccccc3c(=O)c2O)cc1</smiles><smiles>COc1ccc2cc(C=O)ccc2c1</smiles>

$1 c$

2<smiles>COc1ccc2cc(/C=C/C(=O)c3ccccc3O)ccc2c1</smiles>

EPC<smiles>O=Cc1ccccc1</smiles>

$3 c$

$\underset{\mathrm{H}_{2} \mathrm{O}_{2}}{\stackrel{\mathrm{NaOH}}{\longrightarrow}}$<smiles>O=C(/C=C/c1ccccc1)c1ccccc1O</smiles>

$3 d$<smiles>COc1ccc2cc(-c3oc4ccccc4c(=O)c3O)ccc2c1</smiles><smiles></smiles>

PC 


\section{NMR and HRMS spectra}

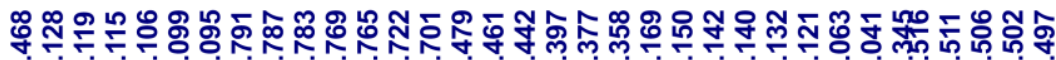
बi

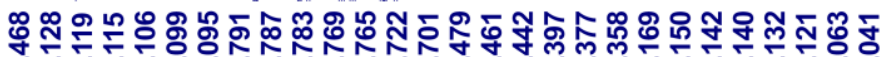

बi

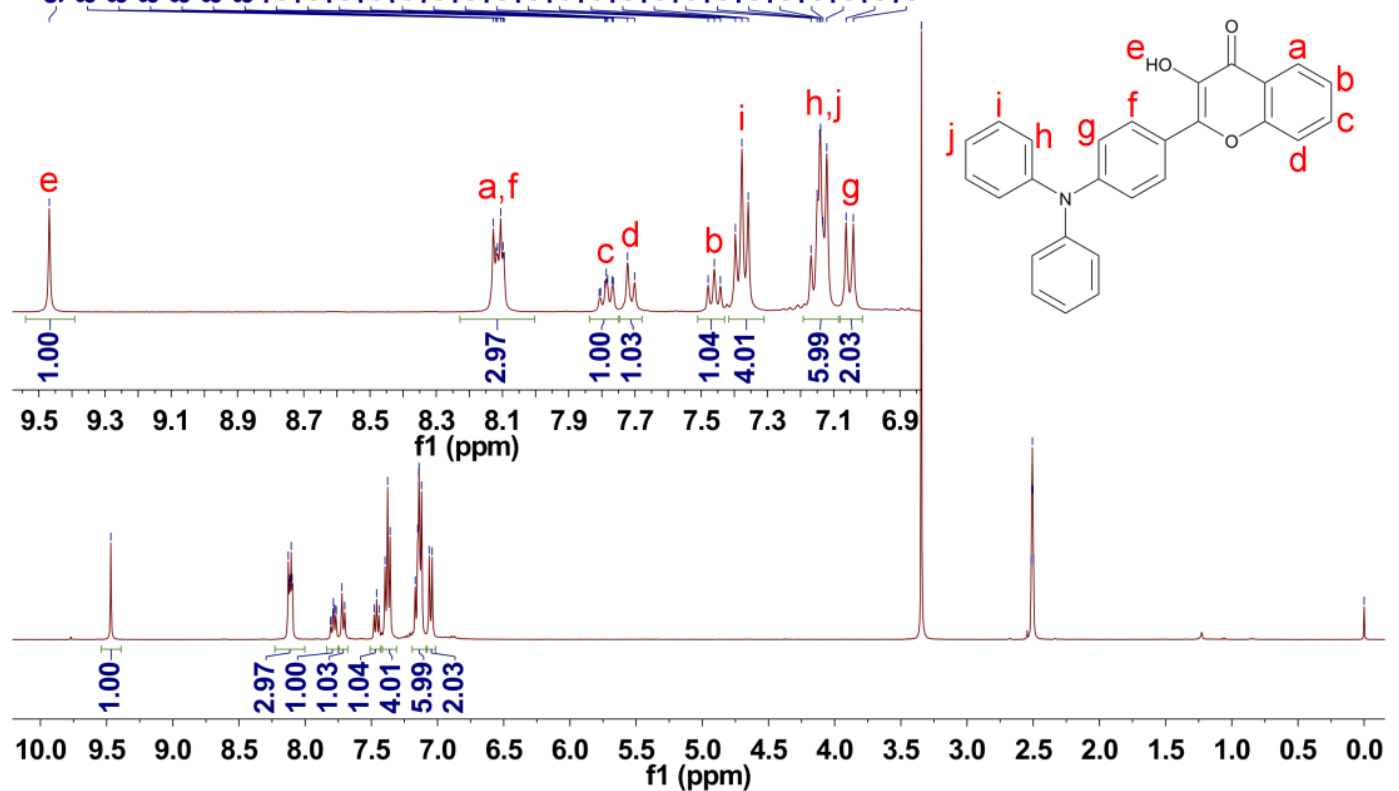

Figure S1. ${ }^{1} \mathrm{H}$ NMR spectrum of PPC in DMSO- $d_{6}$.

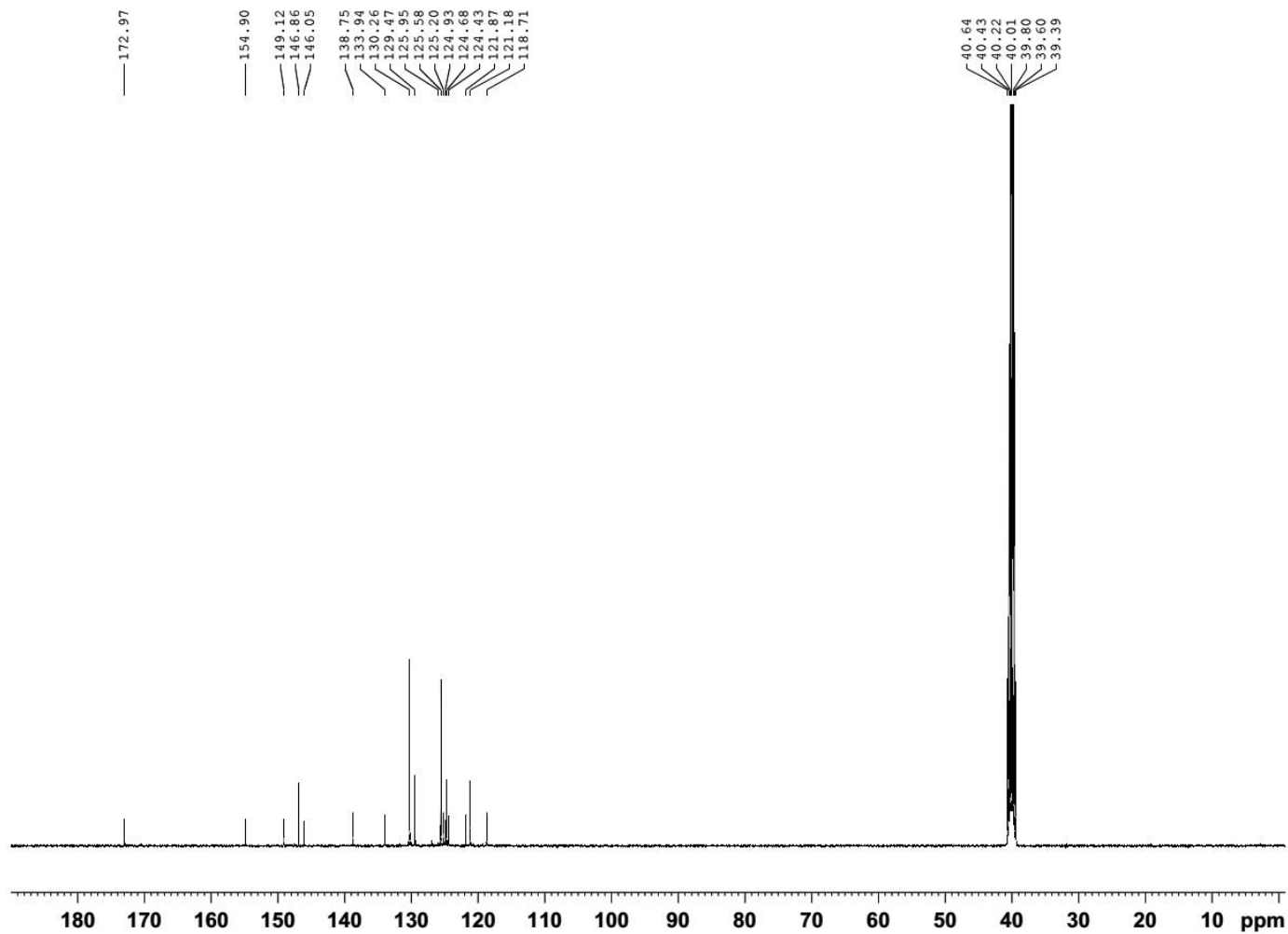

Figure S2. ${ }^{13} \mathrm{C}$ NMR spectrum of PPC in DMSO- $d_{6}$. 


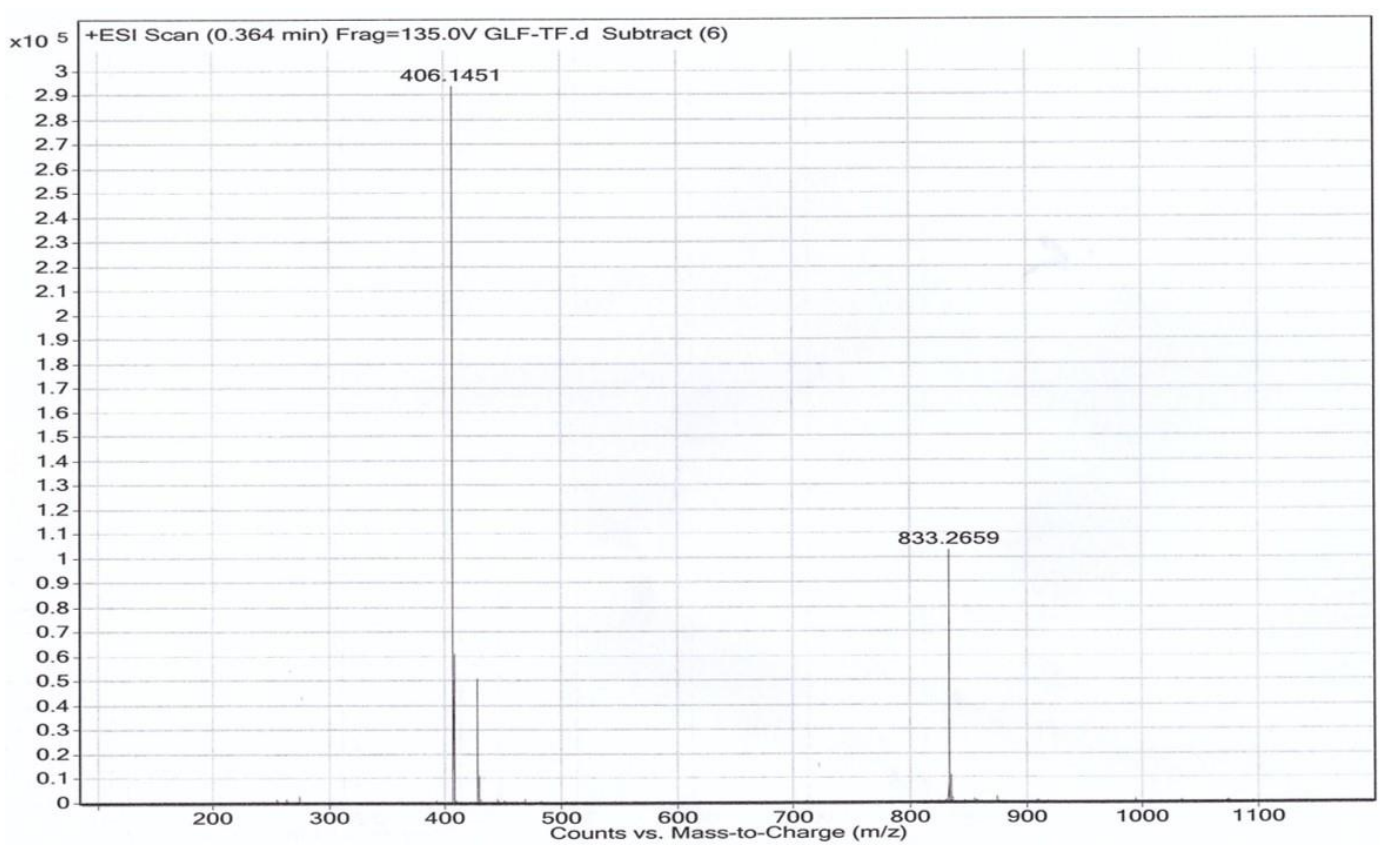

Figure S3. HRMS spectrum of PPC.

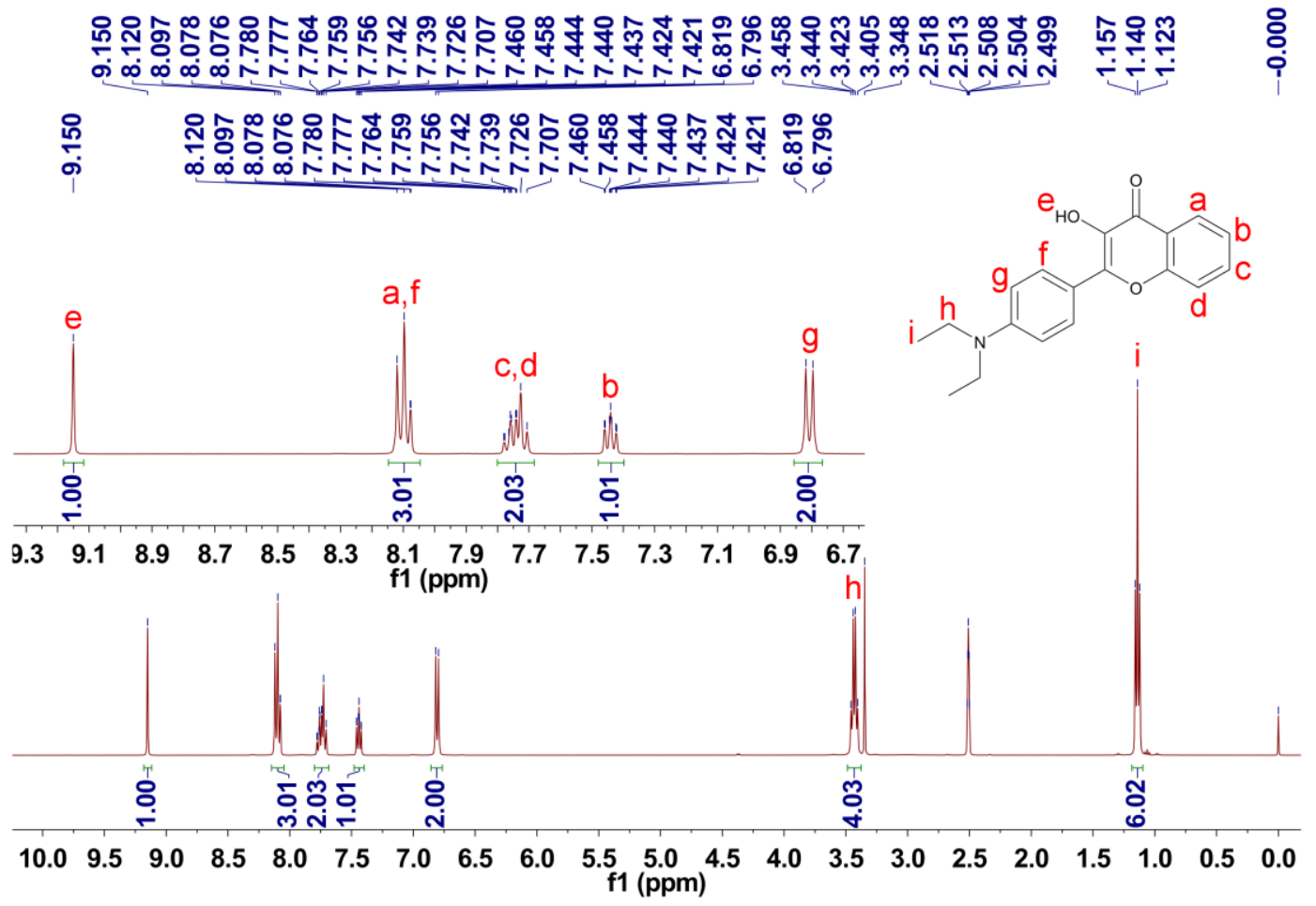

Figure S4. ${ }^{1} \mathrm{H}$ NMR spectrum of EPC in DMSO- $d_{6}$. 


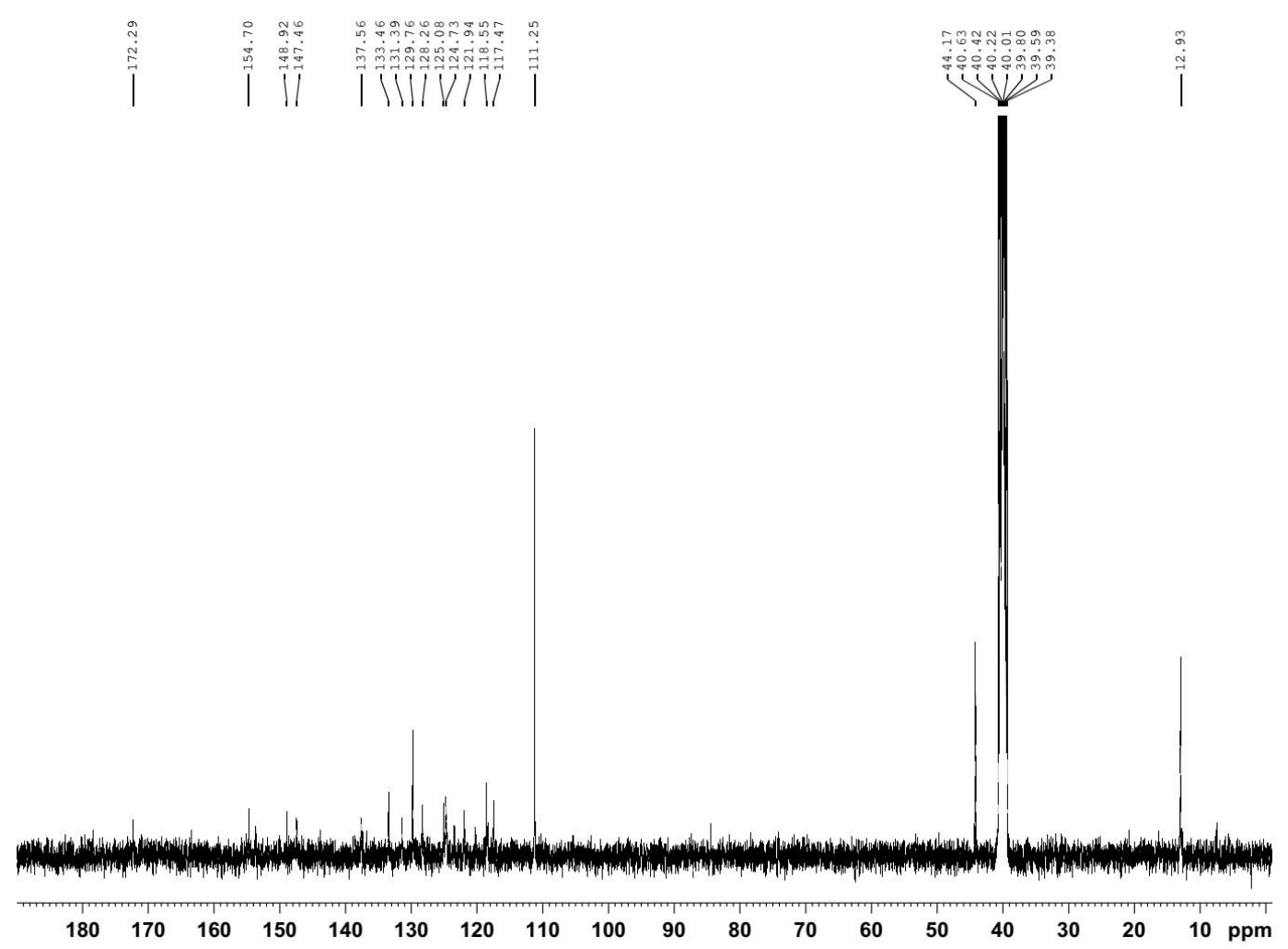

Figure S5. ${ }^{13} \mathrm{C}$ NMR spectrum of EPC in DMSO- $d 6$.

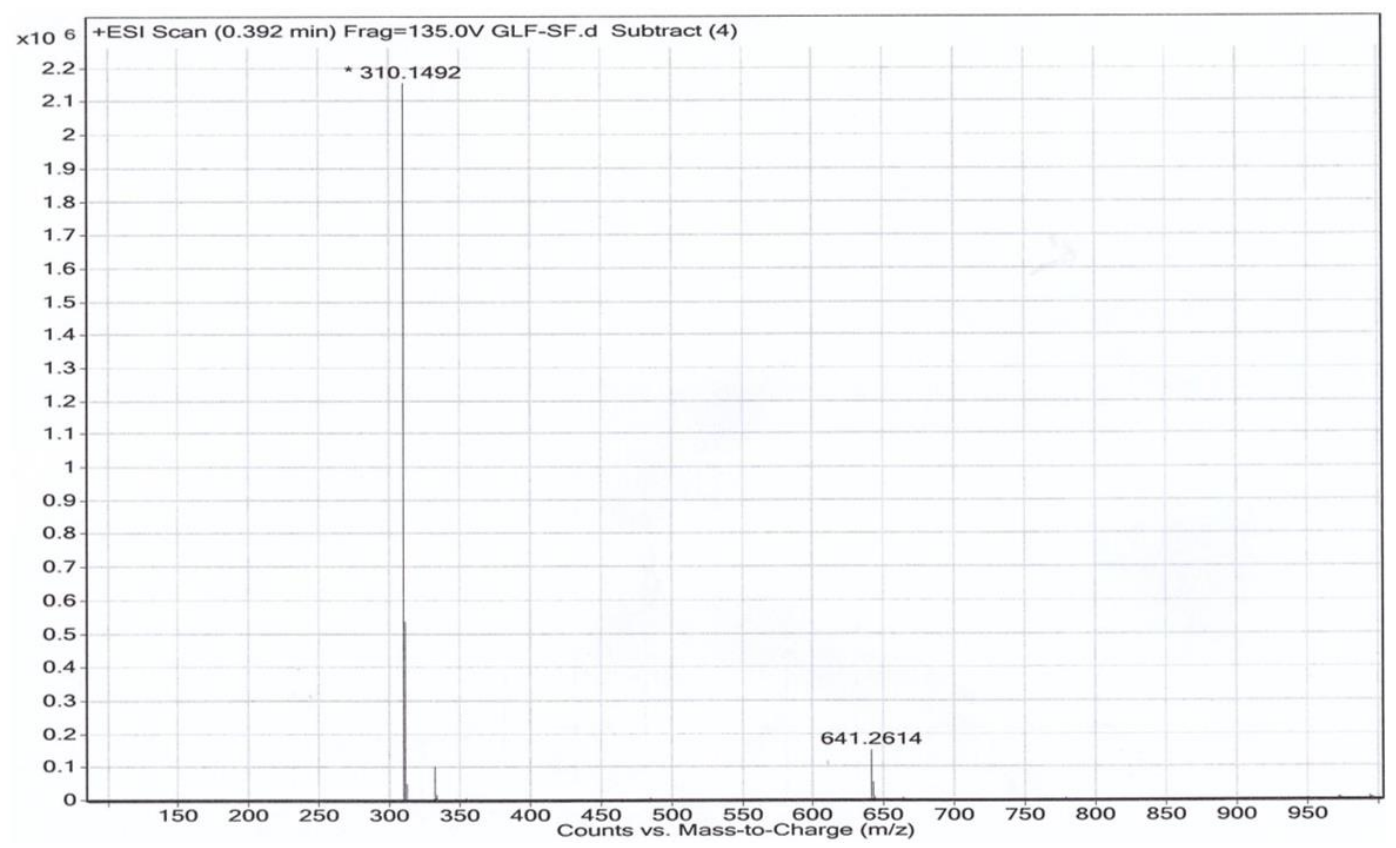

Figure S6. HRMS spectrum of EPC. 


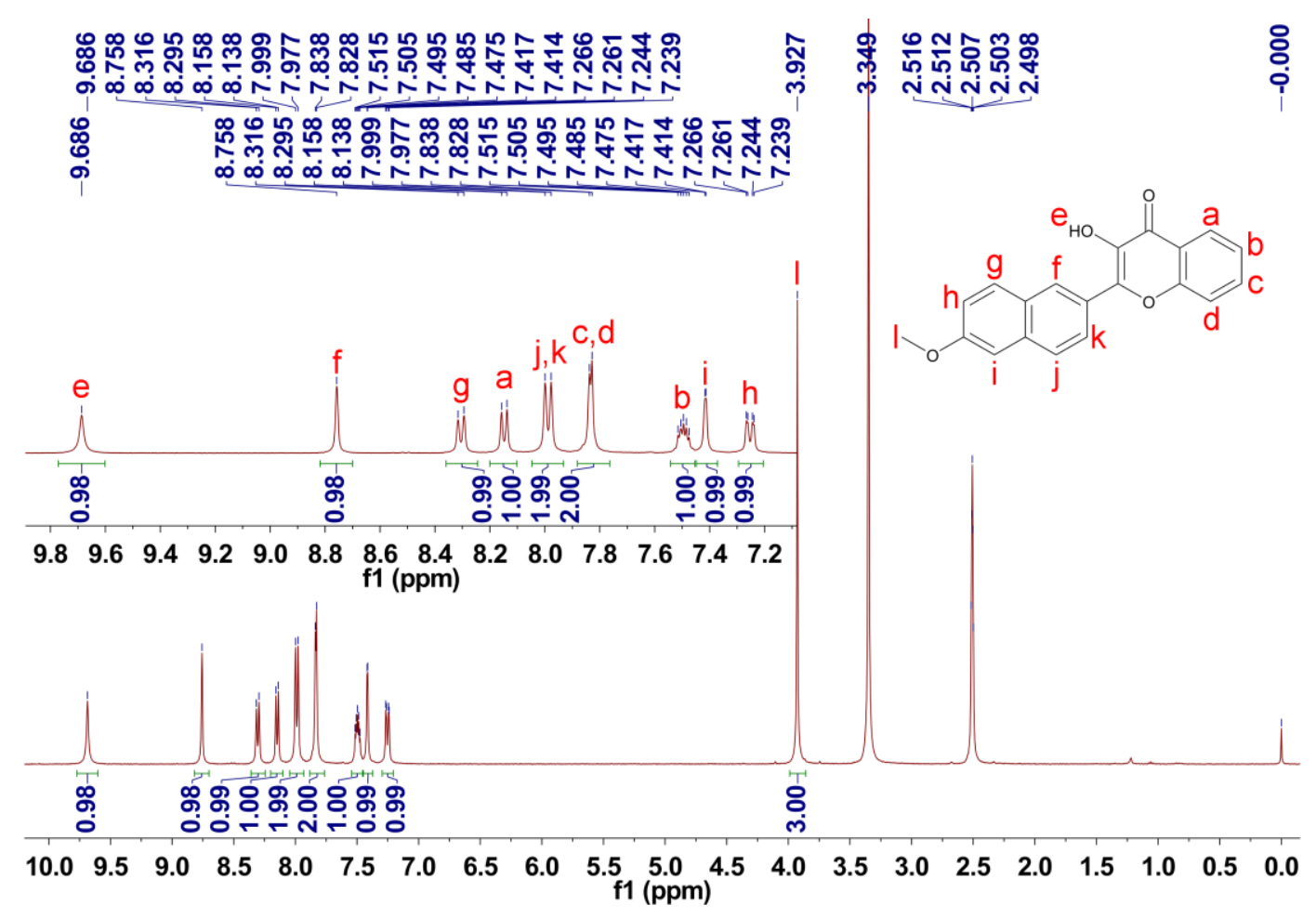

Figure S7. ${ }^{1} \mathrm{H}$ NMR spectrum of MNC in DMSO- $d_{6}$.

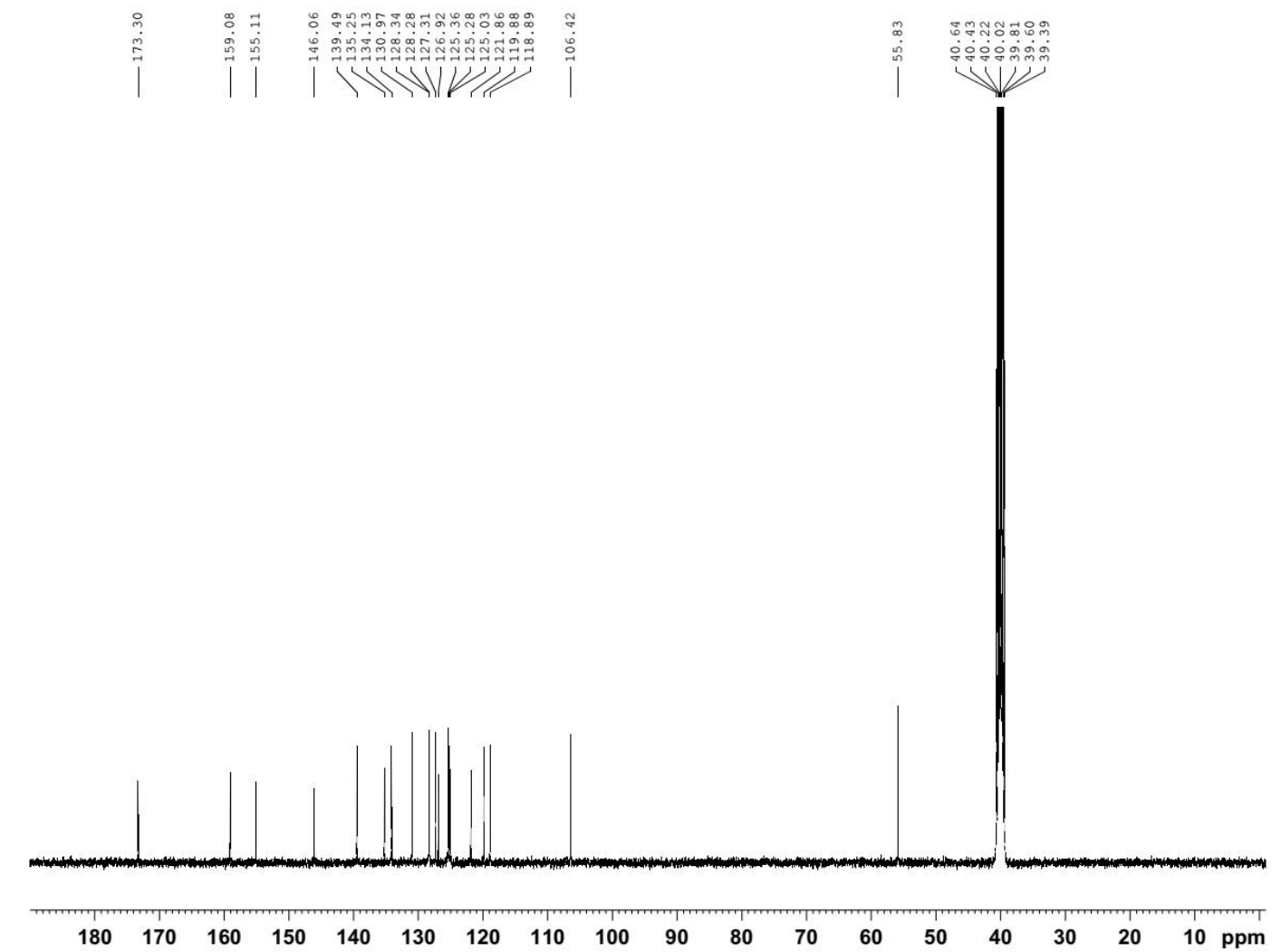

Figure S8. ${ }^{13} \mathrm{C}$ NMR spectrum of MNC in DMSO- $d_{6}$. 


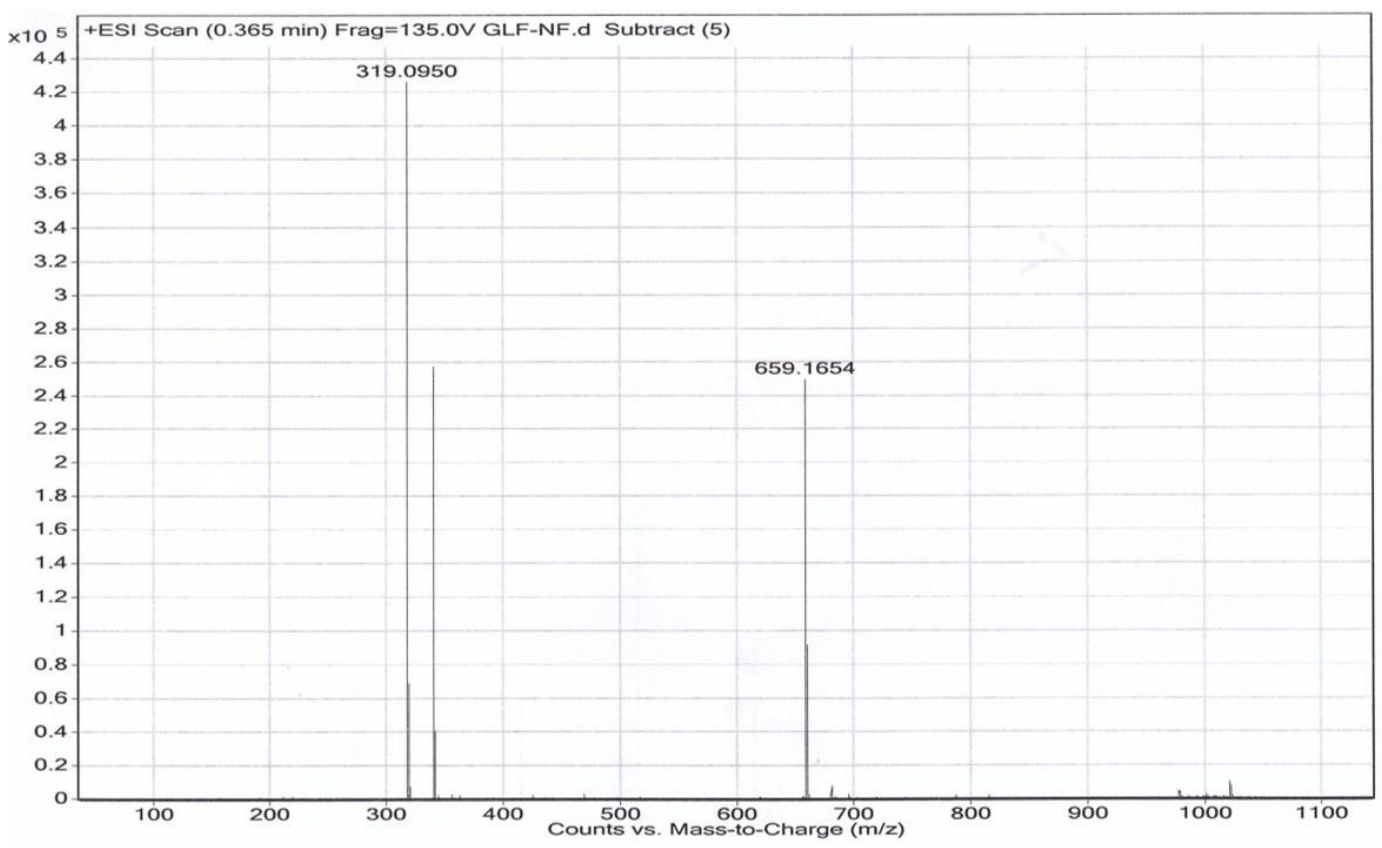

Figure S9. HRMS spectrum of MNC.

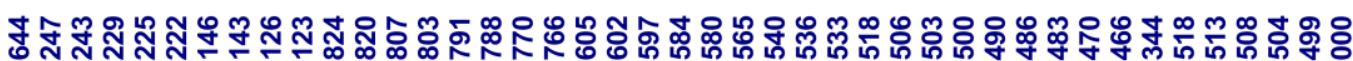

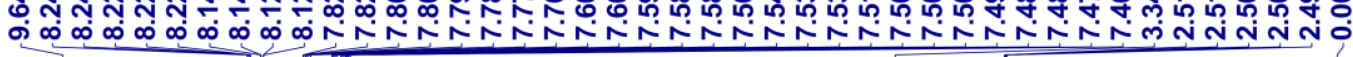

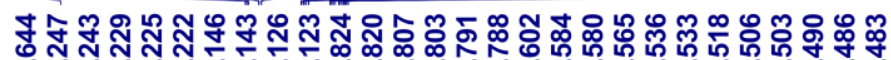

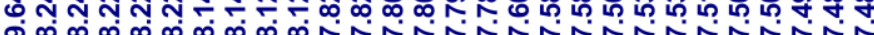

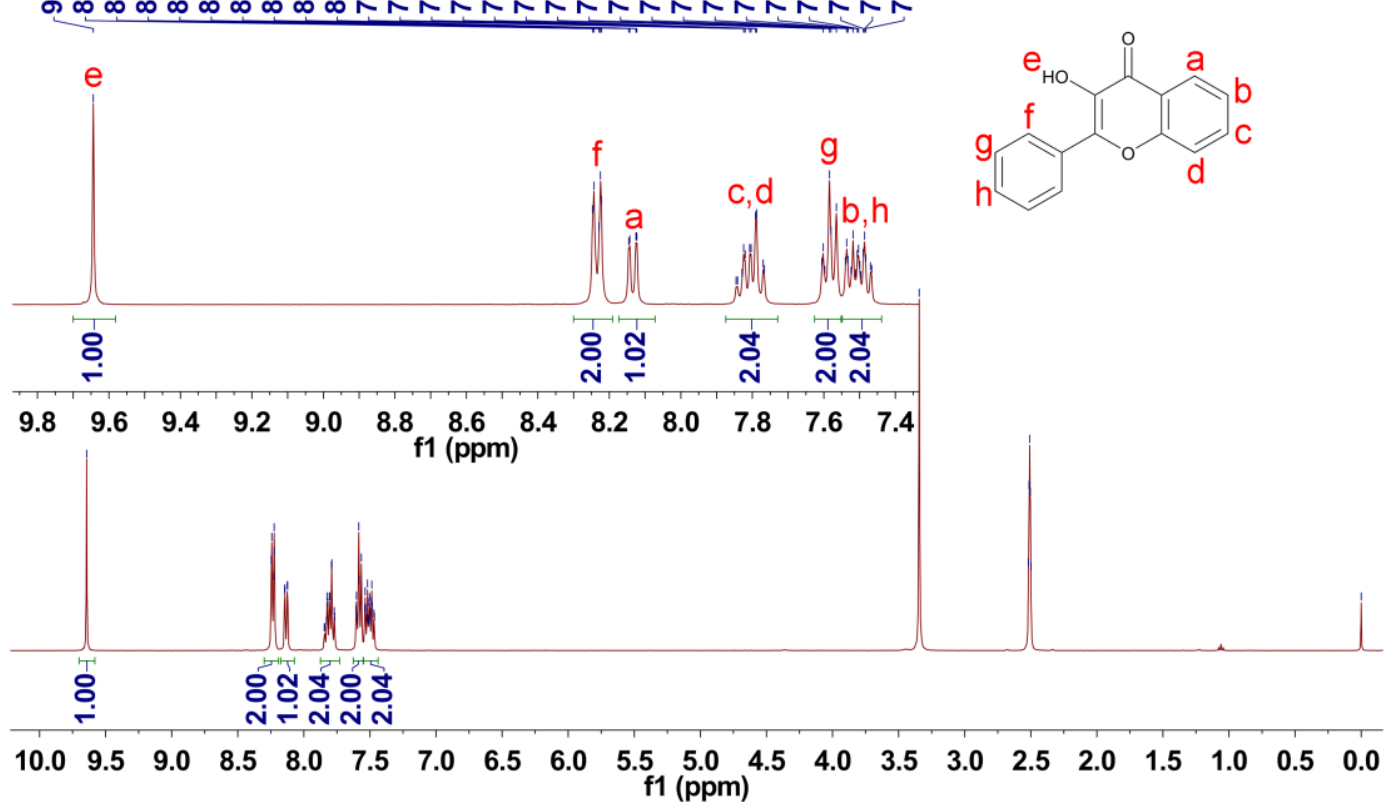

Figure S10. ${ }^{1} \mathrm{H}$ NMR spectrum of PC in DMSO- $d_{6}$. 


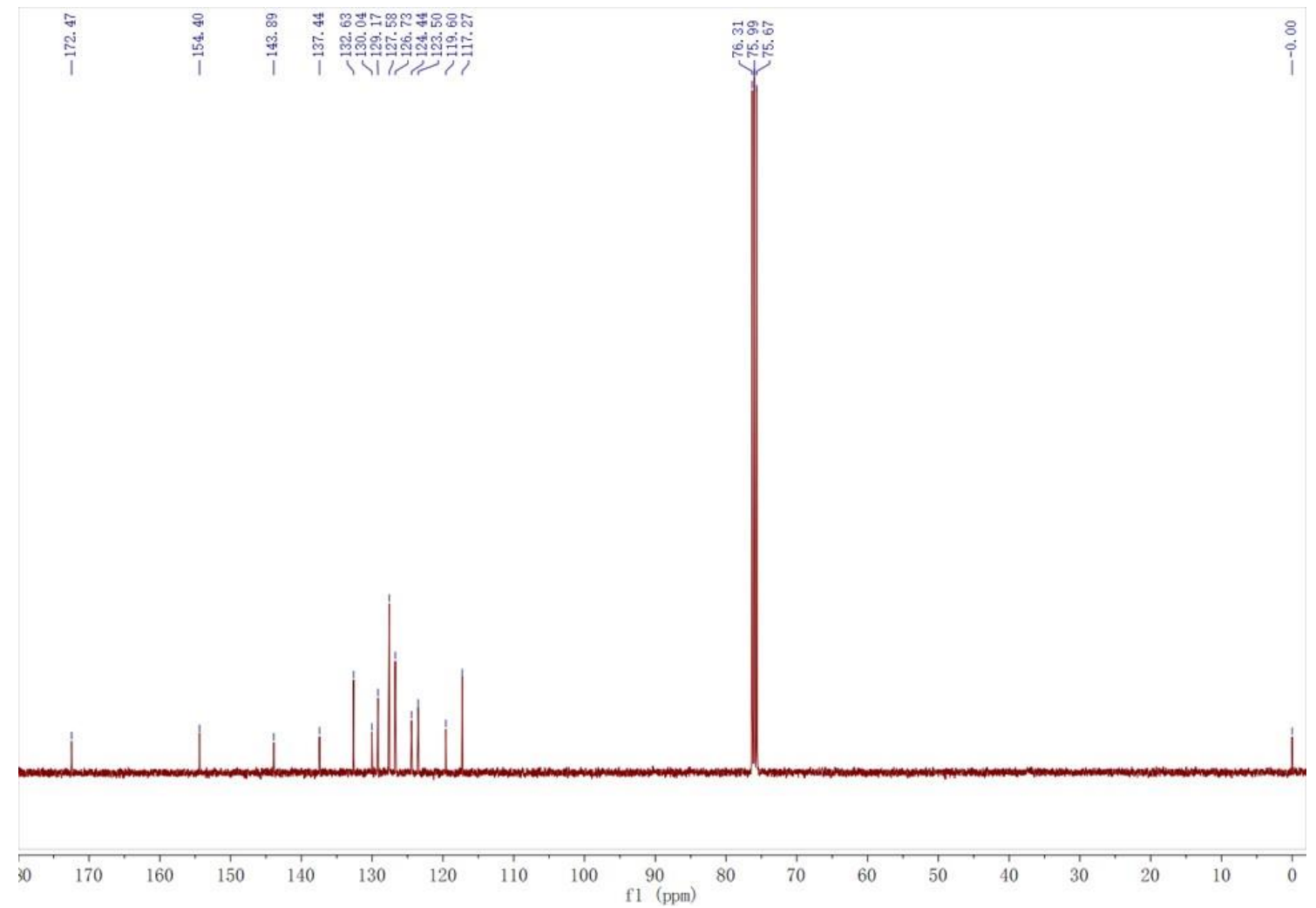

Figure S11. ${ }^{13} \mathrm{C}$ NMR spectrum of $\mathrm{PC}$ in $\mathrm{CDCl}_{3}$.

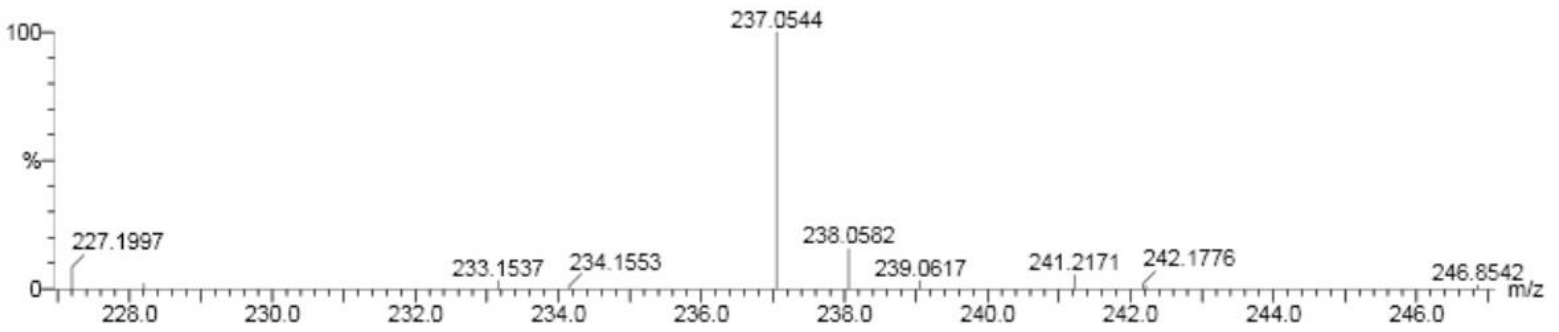

Figure S12. HRMS spectrum of PC. 


\section{Photophysical data}
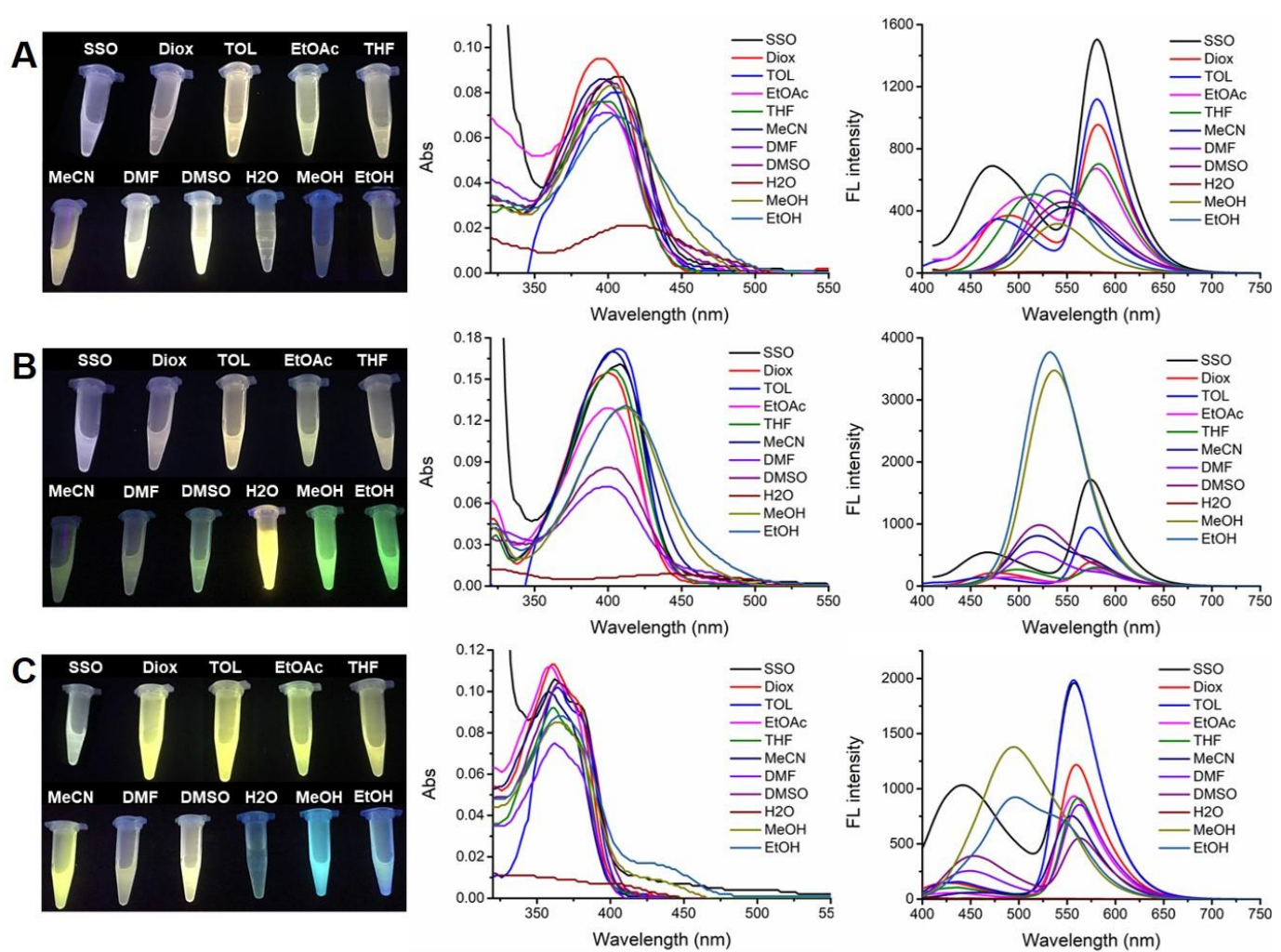

Figure S13. The fluorescent photos under $365 \mathrm{~nm}$ excitation of a hand-held ultraviolet lamp, absorption and FL spectra of (A) PPC, (B) EPC, and (C) MNC in various solvents. SSO: sunflower seed oil; Diox: 1,4-dioxane. For PPC and EPC: $\lambda_{\mathrm{ex}}=405 \mathrm{~nm}$; For MNC: $\lambda_{\mathrm{ex}}=385 \mathrm{~nm}$.

Table S1. The optical properties of PPC, EPC, and $\mathrm{MNC}^{a}$.

\begin{tabular}{|c|c|c|c|c|c|c|c|c|c|c|c|c|}
\hline \multirow{2}{*}{ Solvent } & \multicolumn{4}{|c|}{ PPC } & \multicolumn{4}{|c|}{ EPC } & \multicolumn{4}{|c|}{ MNC } \\
\hline & $\begin{array}{l}\lambda_{\text {Abs }} \\
(\mathrm{nm})\end{array}$ & $\begin{array}{c}\varepsilon \\
\left(10^{4} \mathrm{M}^{-1} \mathrm{~cm}^{-1}\right)\end{array}$ & $\begin{array}{c}\lambda_{\mathrm{em}} \\
(\mathrm{nm})\end{array}$ & $\begin{array}{c}\Phi \\
(\%)\end{array}$ & $\begin{array}{l}\lambda_{\text {Abs }} \\
(\mathrm{nm})\end{array}$ & $\begin{array}{c}\varepsilon \\
\left(10^{4} \mathrm{M}^{-1} \mathrm{~cm}^{-1}\right)\end{array}$ & $\begin{array}{l}\lambda_{\mathrm{em}} \\
(\mathrm{nm})\end{array}$ & $\begin{array}{c}\Phi \\
(\%)\end{array}$ & $\begin{array}{l}\lambda_{\text {Abs }} \\
(\mathrm{nm})\end{array}$ & $\begin{array}{c}\varepsilon \\
\left(10^{4} \mathrm{M}^{-1} \mathrm{~cm}^{-1}\right)\end{array}$ & $\begin{array}{l}\lambda_{\mathrm{em}} \\
(\mathrm{nm})\end{array}$ & $\begin{array}{l}\Phi \\
(\%)\end{array}$ \\
\hline 1,4-dioxane & 394 & 3.32 & $483 / 582$ & 20 & 400 & 3.11 & $472 / 576$ & 3 & 361 & 0.84 & $422 / 559$ & 31 \\
\hline $\mathrm{MeCN}$ & 396 & 3.29 & 550 & 11 & 403 & 2.77 & 519 & 5 & 358 & 0.56 & $456 / 554$ & 26 \\
\hline DMSO & 400 & 2.59 & 548 & 14 & 400 & 2.36 & 521 & 8 & 365 & 1.06 & $454 / 563$ & 14 \\
\hline EtOH & 405 & 2.59 & 534 & 6 & 412 & 1.70 & 532 & 43 & 366 & 1.11 & 496 & 15 \\
\hline
\end{tabular}

${ }^{a}$ Abbreviation: $\lambda_{\mathrm{abs}}=$ absorption maximum; $\lambda_{\mathrm{em}}=$ emission maximum; $\varepsilon=$ molar extinction coefficient; $\Phi=$ fluorescence quantum yield. 
Table S2. The optical properties and the ratios of fluorescence maxima in $N^{*}\left(\lambda_{1}\right)$ and $T^{*}\left(\lambda_{2}\right)$ forms of PPC, EPC, and MNC in 1,4-dioxaneane/water mixtures with different water fractions $\left(f_{\mathrm{w}}\right)$.

\begin{tabular}{cccccc|cc}
\hline$f_{\mathrm{w}}$ (vol\%) & \multicolumn{2}{c|}{ PPC } & \multicolumn{2}{c|}{ EPC } & \multicolumn{2}{c}{ MNC } \\
\hline 0 & $\lambda_{1}$ & $\lambda_{2}$ & $\lambda_{1}$ & $\lambda_{2}$ & $\lambda_{1}$ & $\lambda_{2}$ \\
2 & 483 & 582 & 472 & 576 & 422 & 559 \\
4 & 504 & 581 & 490 & 575 & 436 & 559 \\
6 & 516 & 576 & 499 & 573 & 437 & 559 \\
8 & 525 & $/$ & 505 & 568 & 442 & 559 \\
10 & 532 & $/$ & 509 & $/$ & 447 & 558 \\
\hline
\end{tabular}

Table S3. The CIE1931 coordinates data of PPC, EPC, and MNC in 1,4-dioxane/water mixtures with different water fractions $\left(f_{\mathrm{w}}\right)$.

\begin{tabular}{|c|c|c|c|c|c|c|c|c|c|c|c|c|c|c|c|c|c|c|}
\hline \multirow{3}{*}{ CIE1931 } & \multicolumn{6}{|c|}{ PPC } & \multicolumn{6}{|c|}{ EPC } & \multicolumn{6}{|c|}{ MNC } \\
\hline & \multicolumn{6}{|c|}{$\mathrm{f}_{\mathrm{w}}(\mathrm{vol} \%)$} & \multicolumn{6}{|c|}{$f_{w}(v o l \%)$} & \multicolumn{6}{|c|}{$f_{w}(v o l \%)$} \\
\hline & 0 & 2 & 4 & 6 & 8 & 10 & 0 & 2 & 4 & 6 & 8 & 10 & 0 & 2 & 4 & 6 & 8 & 10 \\
\hline$x$ & 0.44 & 0.38 & 0.35 & 0.34 & 0.34 & 0.34 & 0.39 & 0.31 & 0.28 & 0.26 & 0.25 & 0.25 & 0.42 & 0.41 & 0.40 & 0.39 & 0.38 & 0.37 \\
\hline$y$ & 0.41 & 0.46 & 0.50 & 0.53 & 0.55 & 0.56 & 0.38 & 0.41 & 0.44 & 0.49 & 0.52 & 0.55 & 0.51 & 0.51 & 0.49 & 0.48 & 0.47 & 0.46 \\
\hline
\end{tabular}
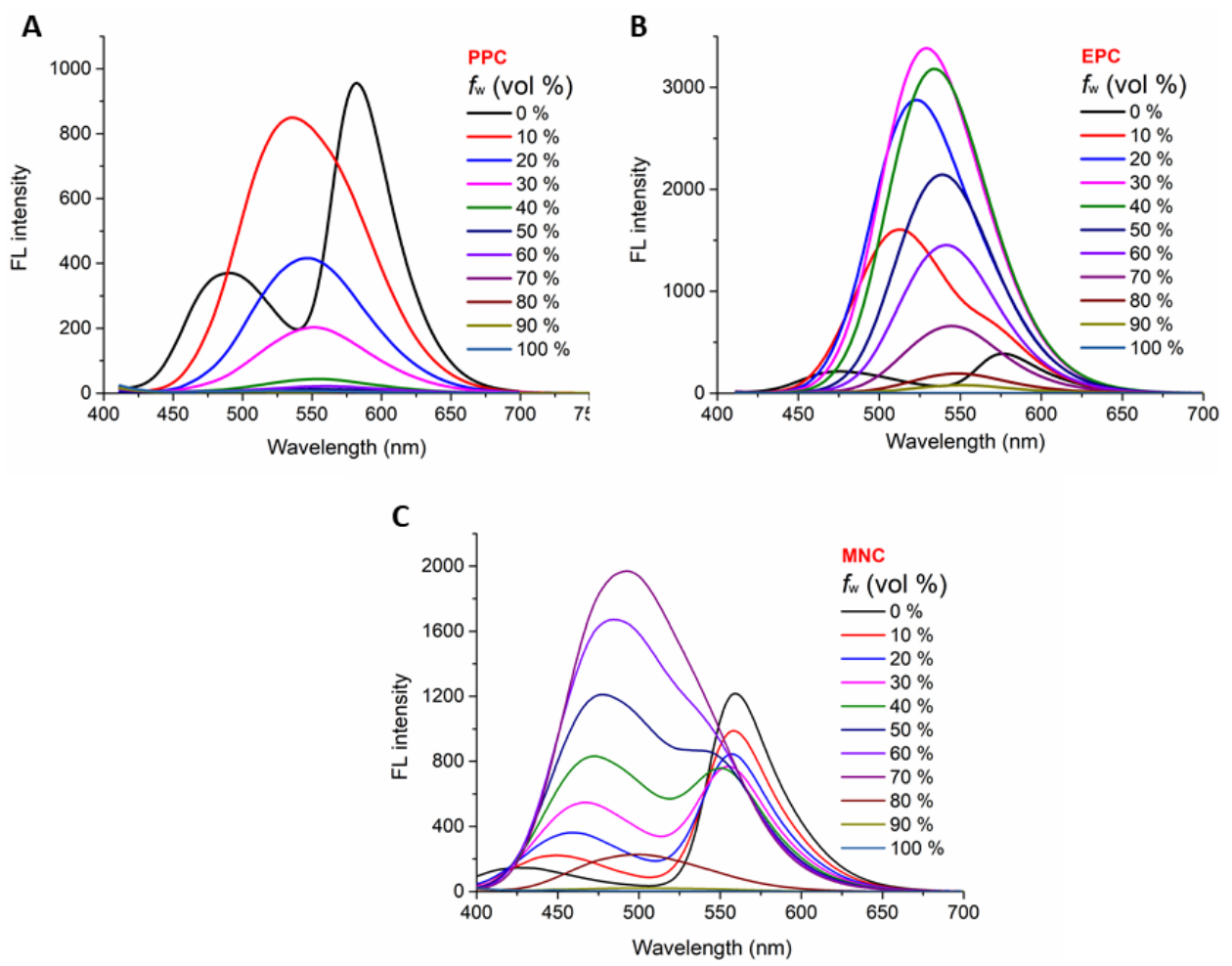

Figure S14. The fluorescence spectra of (A) PPC, (B) EPC, and (C) MNC in 1,4-dioxane/water mixtures with different water fractions $\left(f_{\mathrm{w}}\right)$. For PPC and EPC: $\lambda_{\mathrm{ex}}=405 \mathrm{~nm}$; For MNC: $\lambda_{\mathrm{ex}}=385 \mathrm{~nm}$. 

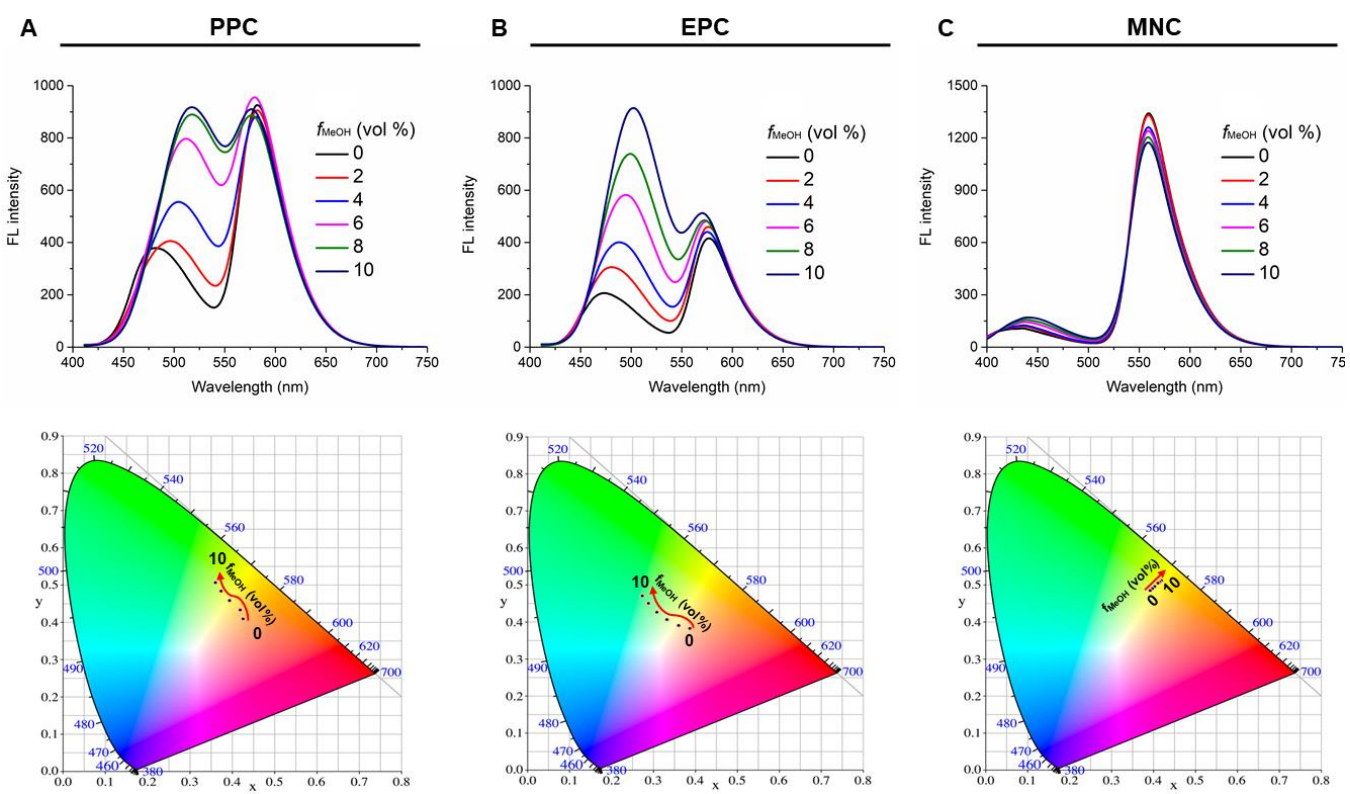

Figure S15. The fluorescence spectra and CIE1931 coordinates of (A) PPC, (B) EPC, and (C) MNC in 1,4-dioxane/MeOH mixtures with different $\mathrm{MeOH}$ fractions $\left(f_{\mathrm{MeOH}}\right)$. For PPC and $\mathrm{EPC}: \lambda_{\mathrm{ex}}=405$ $\mathrm{nm}$; for MNC: $\lambda_{\mathrm{ex}}=385 \mathrm{~nm}$.

Table S4. The CIE1931 coordinate data of PPC, EPC and MNC in 1,4-dioxane/MeOH mixtures with different $\mathrm{MeOH}$ fractions $\left(f_{\mathrm{MeOH}}\right)$.

\begin{tabular}{|c|c|c|c|c|c|c|c|c|c|c|c|c|c|c|c|c|c|c|}
\hline \multirow{3}{*}{ ClE1931 } & \multicolumn{6}{|c|}{ PPC } & \multicolumn{6}{|c|}{ EPC } & \multicolumn{6}{|c|}{ MNC } \\
\hline & \multicolumn{6}{|c|}{$f_{\mathrm{Mеон}}(\mathrm{vol} \%)$} & \multicolumn{6}{|c|}{$f_{\mathrm{MeOH}}(\mathrm{vol} \%)$} & \multicolumn{6}{|c|}{$f_{\text {Меон }}(\mathrm{vol} \%)$} \\
\hline & 0 & 2 & 4 & 6 & 8 & 10 & 0 & 2 & 4 & 6 & 8 & 10 & 0 & 2 & 4 & 6 & 8 & 10 \\
\hline$x$ & 0.43 & 0.42 & 0.40 & 0.37 & 0.36 & 0.36 & 0.39 & 0.36 & 0.33 & 0.31 & 0.29 & 0.27 & 0.42 & 0.41 & 0.41 & 0.40 & 0.40 & 0.39 \\
\hline y & 0.41 & 0.43 & 0.46 & 0.48 & 0.51 & 0.51 & 0.38 & 0.39 & 0.41 & 0.43 & 0.45 & 0.47 & 0.51 & 0.51 & 0.50 & 0.50 & 0.49 & 0.48 \\
\hline
\end{tabular}



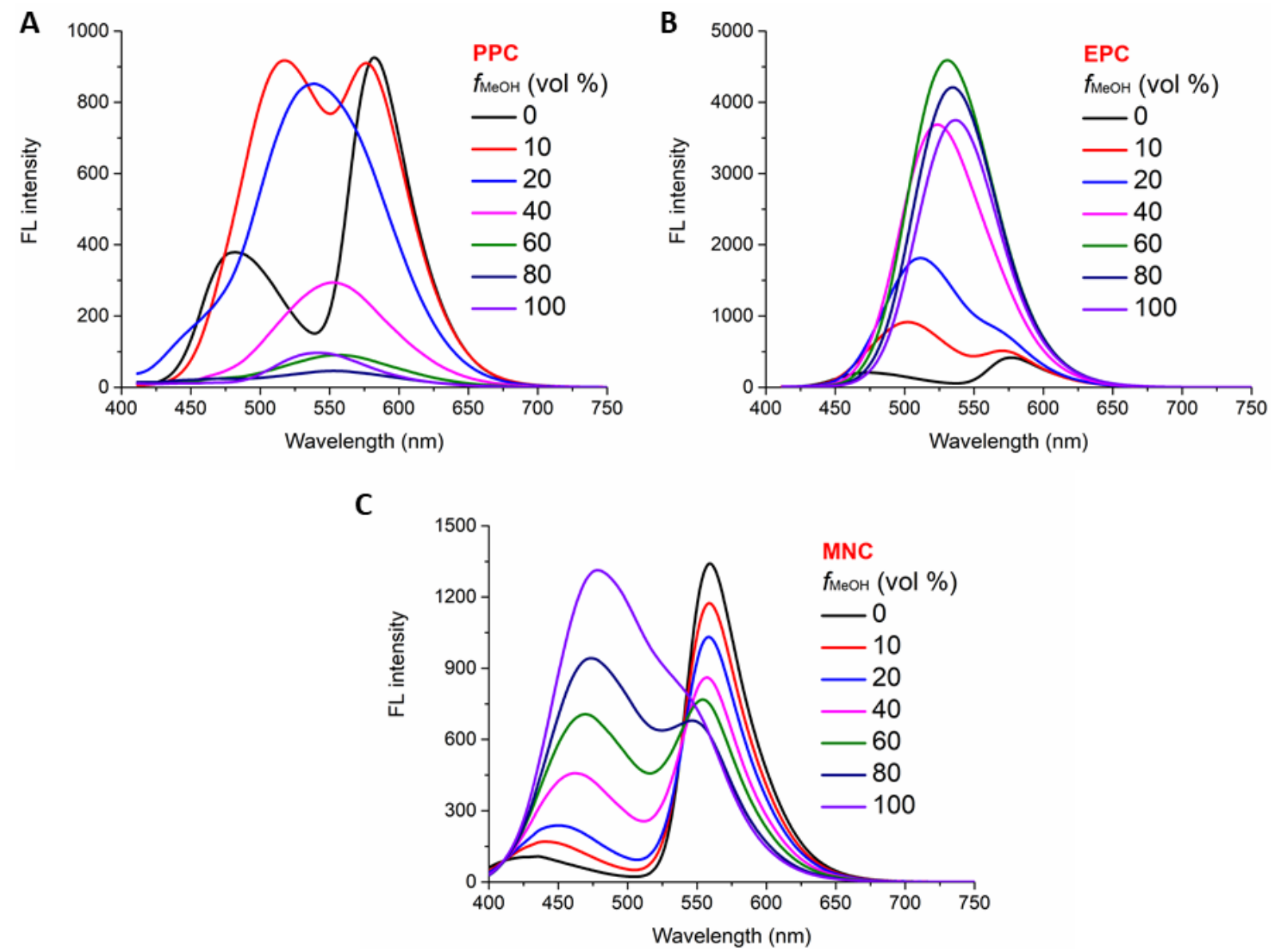

Figure S16. The fluorescence spectra of (A) PPC, (B) EPC, and (C) MNC in 1,4-dioxane/MeOH mixtures with different $\mathrm{MeOH}$ fractions $\left(f_{\mathrm{MeOH}}\right)$. For PPC and EPC: $\lambda_{\mathrm{ex}}=405 \mathrm{~nm}$; For MNC: $\lambda_{\mathrm{ex}}=385$ nm.

A<smiles>O=c1c(O)c(-c2ccccc2)oc2ccccc12</smiles>
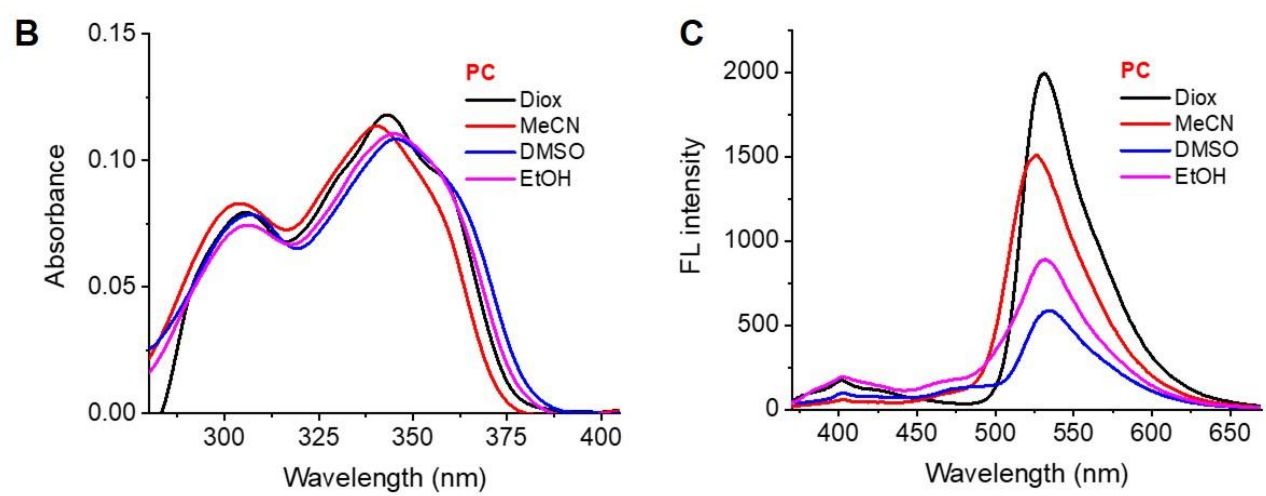

Figure S17. (A) The chemical structure of the control ESIPT dye 3-hydroxyflavone and (B) its absorption and (C) fluorescence spectra in different solvents. Diox: 1,4-dioxane. $\lambda_{\mathrm{ex}}=360 \mathrm{~nm}$. 


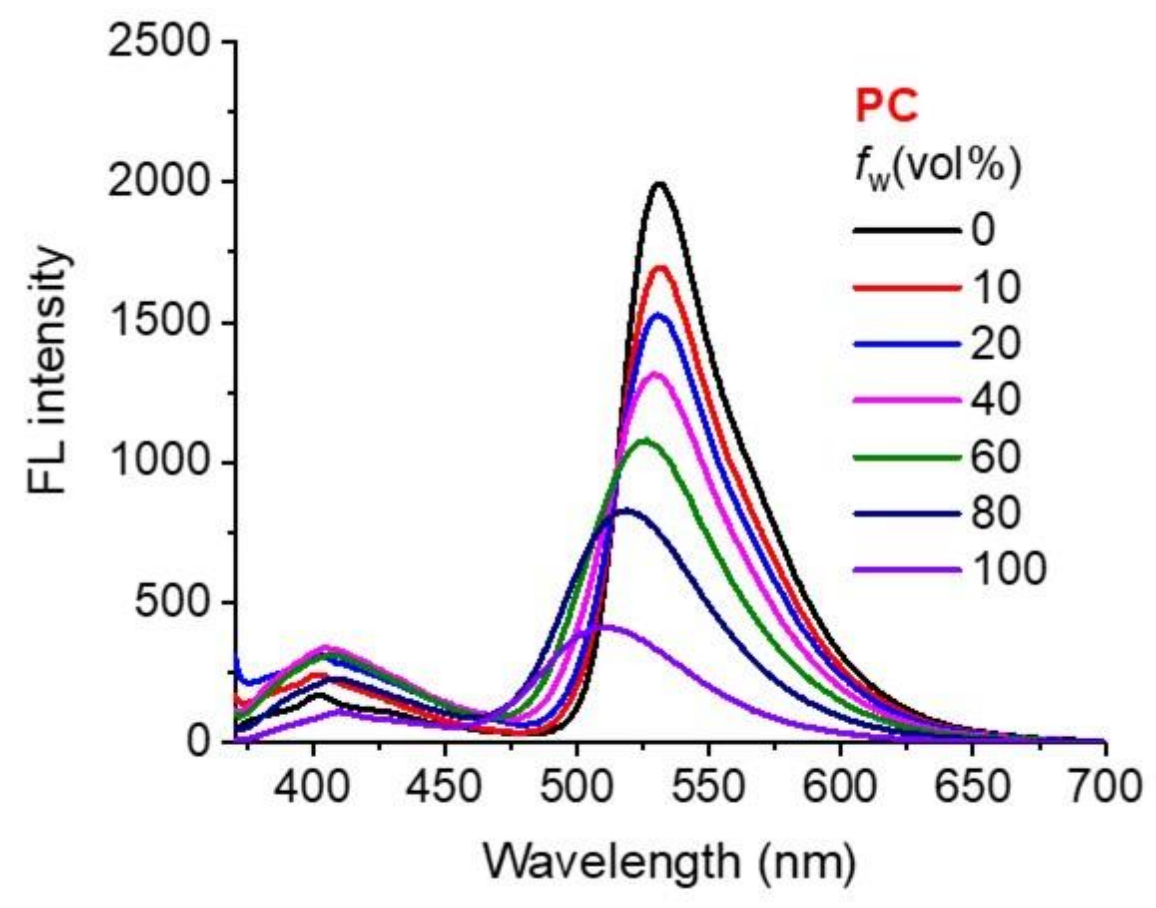

Figure S18. The fluorescence spectra of PC in 1,4-dioxane/water mixtures with different water fractions $\left(f_{\mathrm{w}}\right)$ from 0 to $100 \% . \lambda_{\mathrm{ex}}=360 \mathrm{~nm}$.

Table S5. The CIE1931 coordinates data of PC in 1,4-dioxane/water mixtures with different water fractions $\left(f_{\mathrm{w}}\right)$.

\begin{tabular}{ccccccc}
\hline & \multicolumn{6}{c}{ PC } \\
\cline { 2 - 7 } CIE1931 & 0 & 2 & 4 & 6 & 8 & 10 \\
\hline & 0.316 & 0.316 & 0.313 & 0.310 & 0.308 & 0.307 \\
$\mathrm{y}$ & 0.614 & 0.617 & 0.610 & 0.604 & 0.601 & 0.599 \\
\hline
\end{tabular}



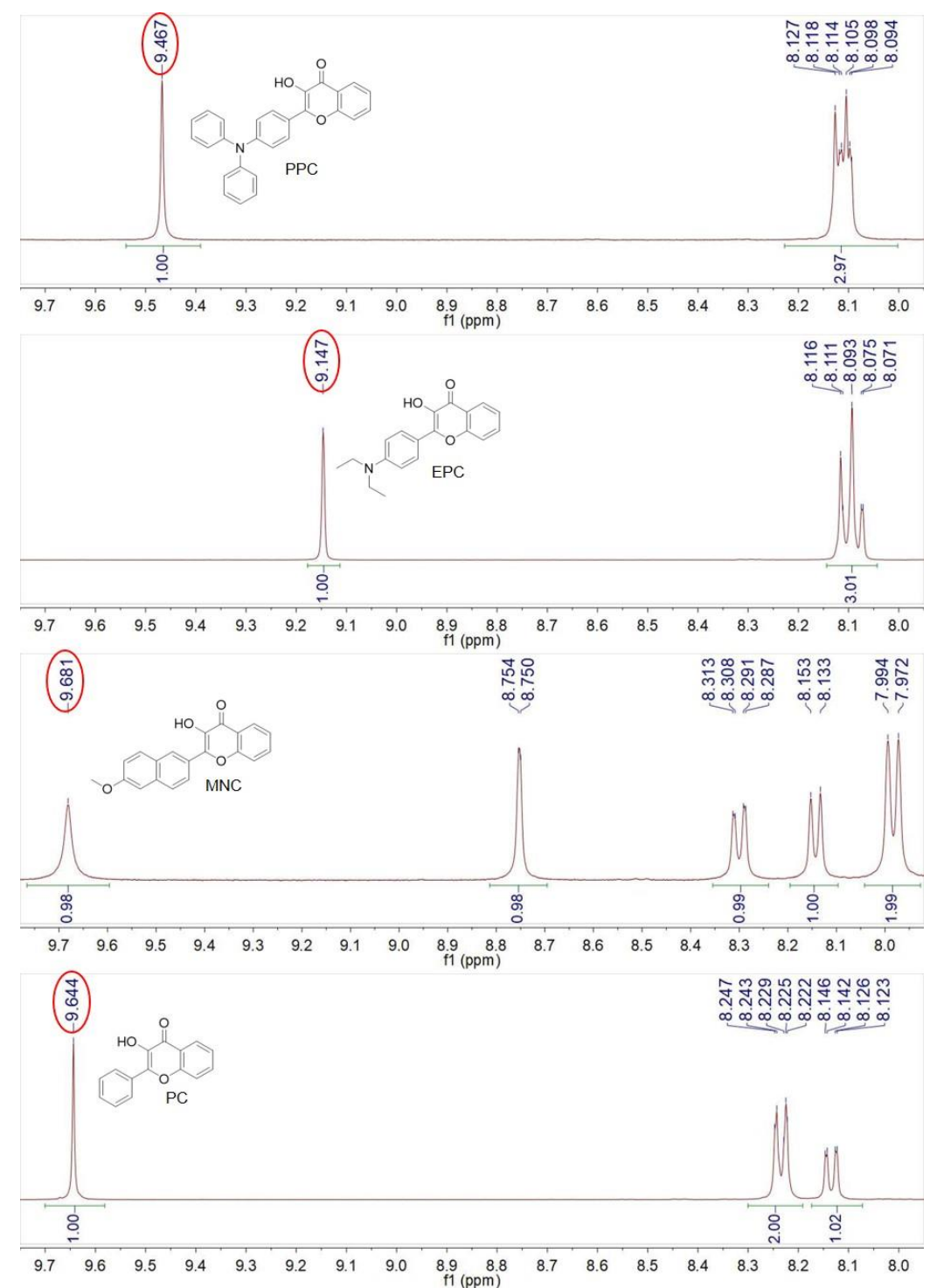

Figure S19. The ${ }^{1} \mathrm{H}$ NMR chemical shift of hydroxyl hydrogen of PPC,EPC, MNC, and PC.

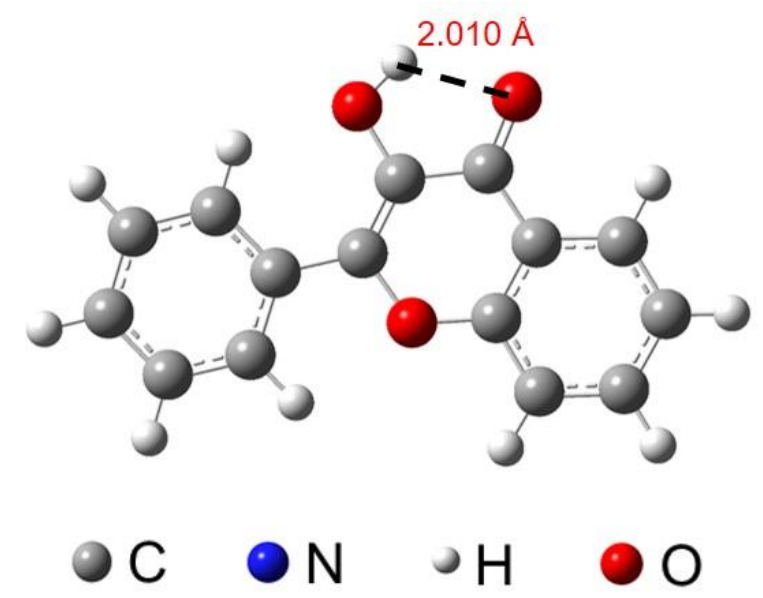

Figure S20. The optimized structure of PC. 


\section{Imaging data}

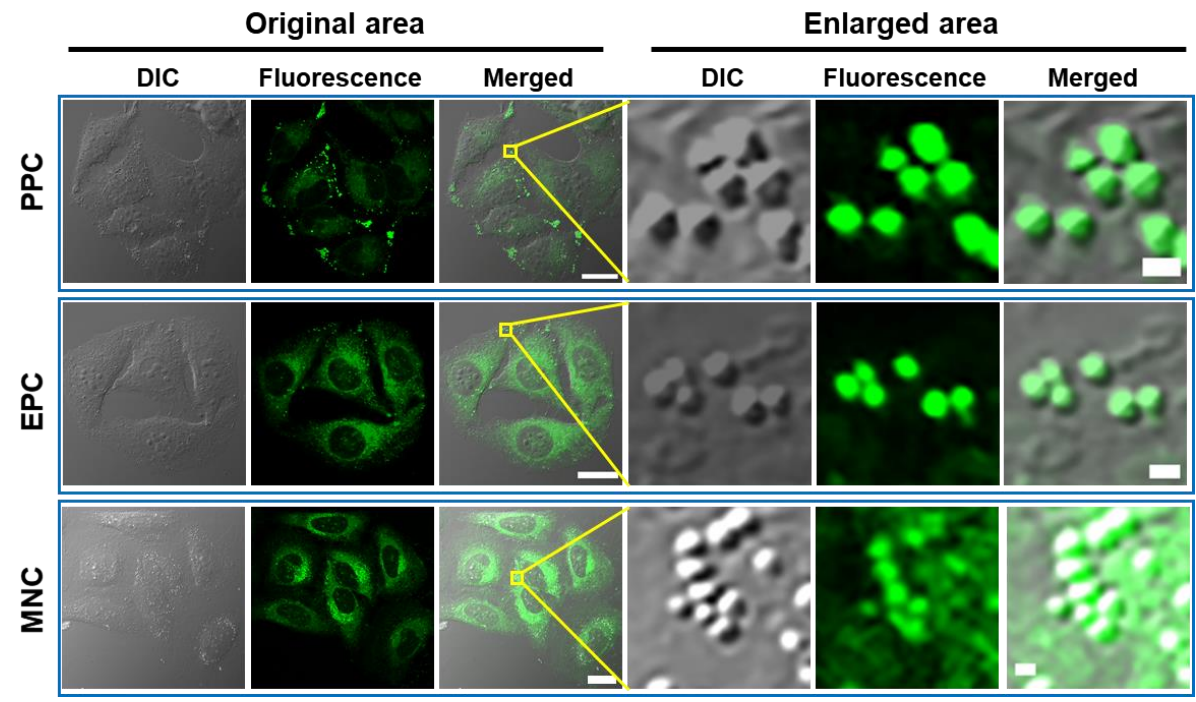

Figure S21. Confocal fluorescent images of HeLa cells stained with PPC, EPC and MNC. $\lambda_{\mathrm{ex}}=405$ $\mathrm{nm}, \lambda_{\mathrm{em}}=500-600 \mathrm{~nm}$. Scale bar $=20 \mu \mathrm{m}$ (original area) or $1 \mu \mathrm{m}($ enlarged area $)$.

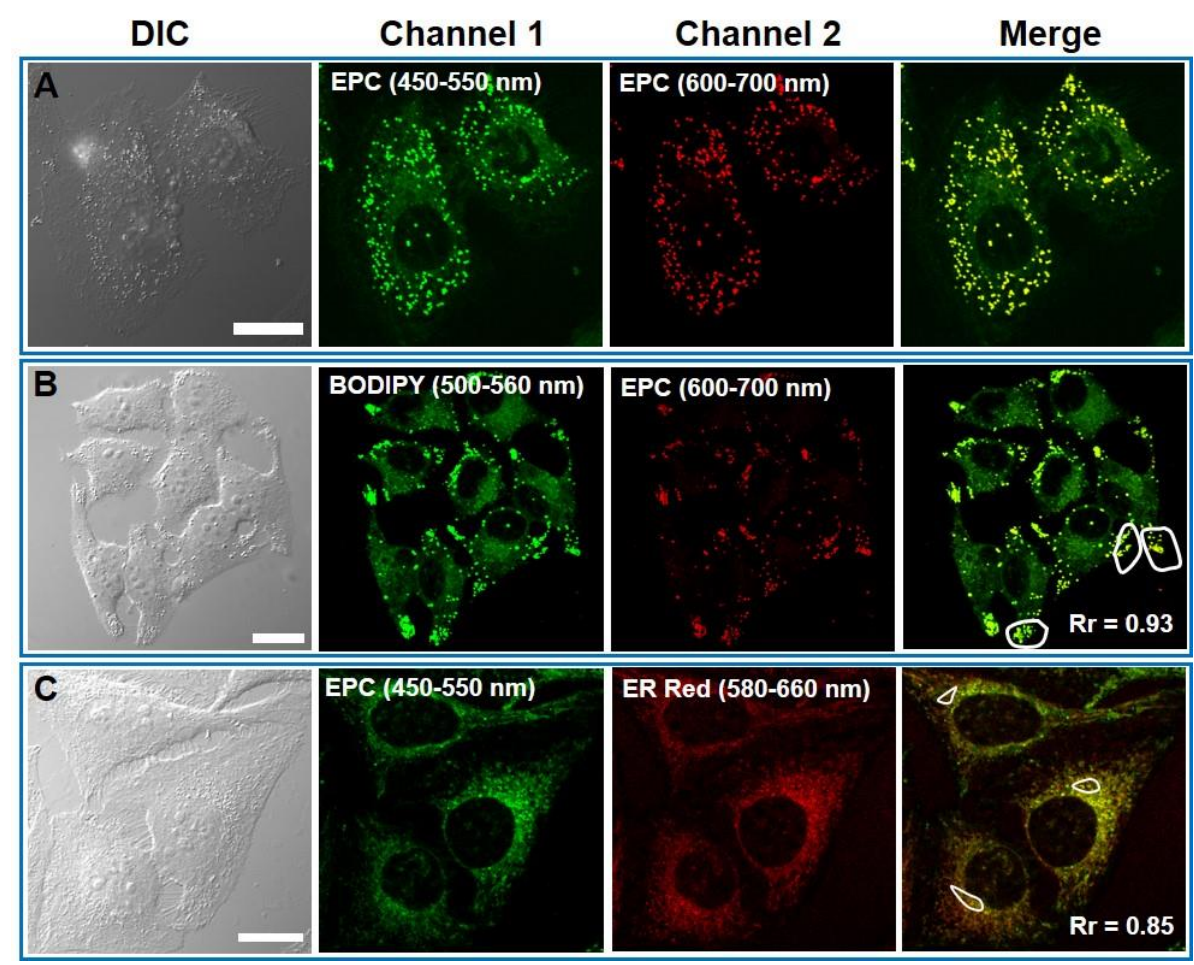

Figure S22. (A) Confocal fluorescent images of HeLa cells stained with EPC. The colocalization experiments of HeLa cells stained with EPC and (B) BODIPY 493/503 or (C) ER Red. Rr: the average colocalization coefficient of these ROIs indicated by the white circles. $\lambda_{\mathrm{ex}}(\mathrm{EPC})=405 \mathrm{~nm}$; $\lambda_{\mathrm{ex}}$ $($ BODIPY $)=473 \mathrm{~nm} ; \lambda_{\text {ex }}($ ER Red $)=543 \mathrm{~nm}$. Scale bar $=20 \mu \mathrm{m}$ 

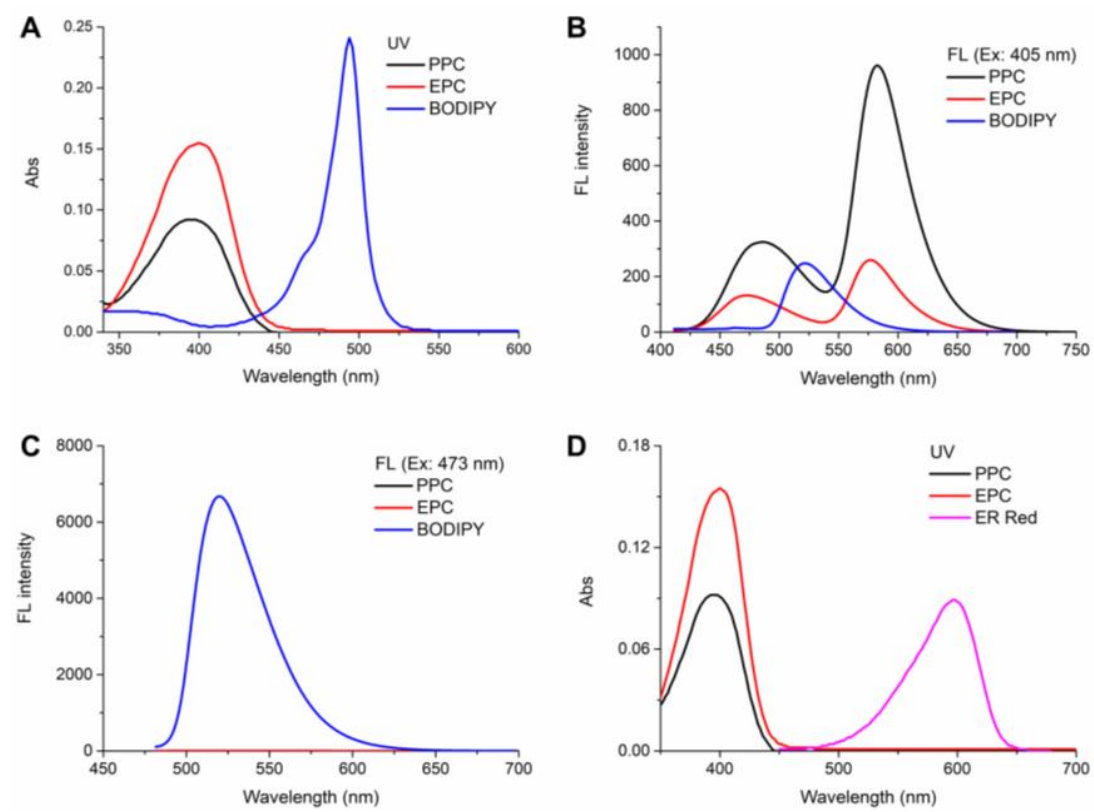

Figure S23. (A) The UV spectra and (B-C) fluorescence spectra of PPC, EPC, and BODIPY excited by $405 \mathrm{~nm}$ and $473 \mathrm{~nm}$. (D) The UV spectra of PPC, EPC, and ER-Tracker Red.
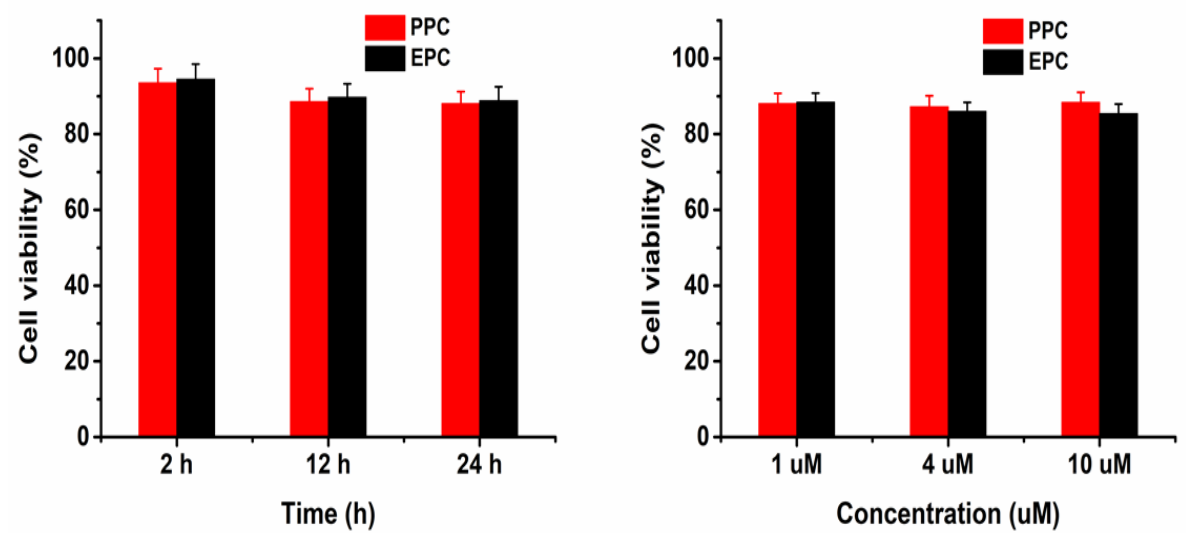

Figure S24. MTT results of Hela cells incubated with PPC and EPC under different conditions.
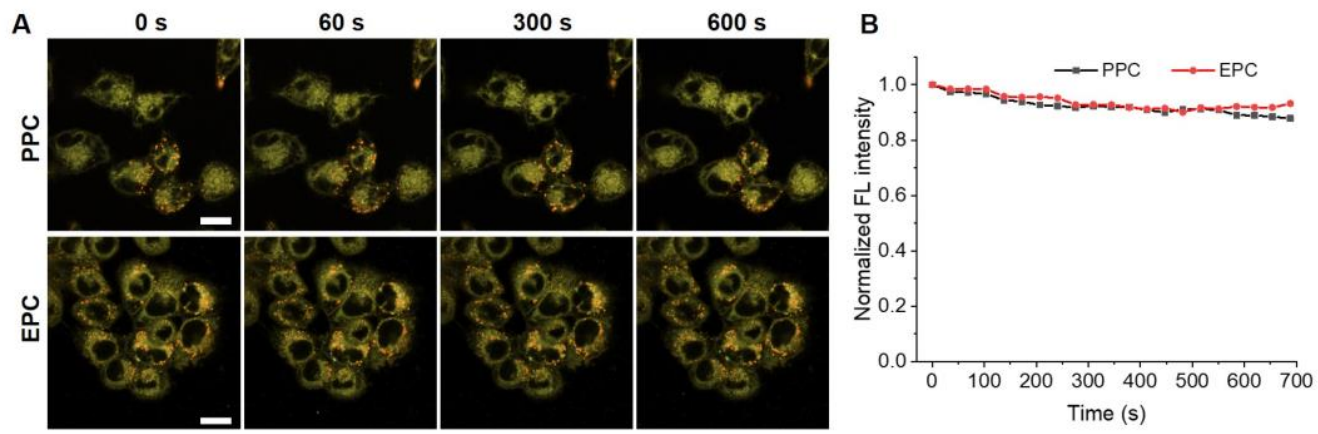

Figure S25. (A) Real-color fluorescent images of HeLa cells incubated with PPC and EPC in Lambda mode under continuous 405-nm laser irradiation at different time points. (B) The normalized fluorescence intensity of PPC and EPC at different time points. 

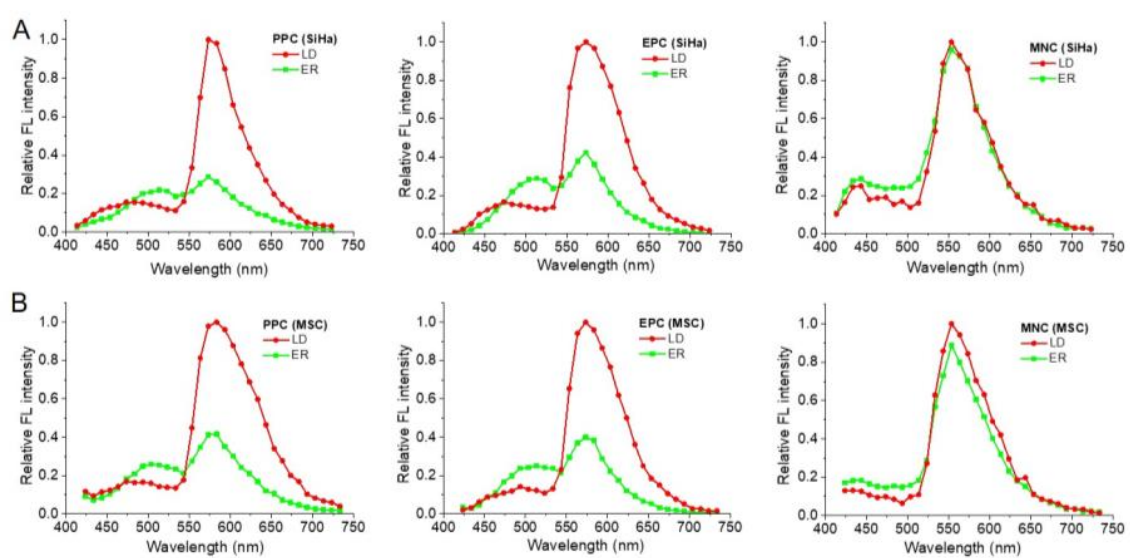

Figure S26. In situ fluorescence spectra of orange-yellow LDs and green ER regions in (A) live SiHa cells and (B) MSCs stained with $1 \mu \mathrm{M}$ PPC, EPC, and MNC for $2 \min . \lambda_{\mathrm{ex}}=405 \mathrm{~nm}$.

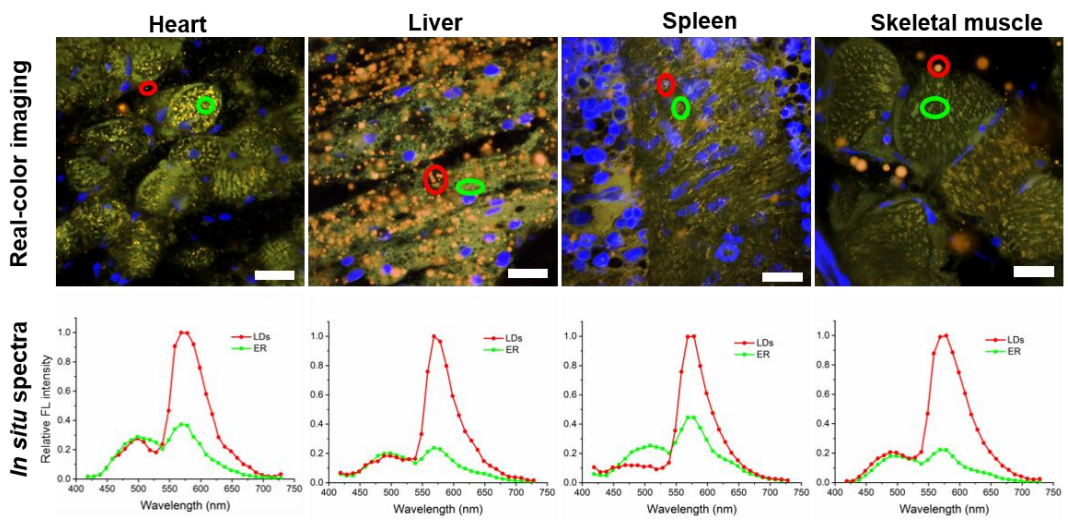

Figure S27. Real-color confocal fluorescent images of PPC merged with the pseudo-color images of SYTO 61 (blue) in various tissues, as well as the corresponding in situ fluorescence spectra in LDs (indicated by the red circles) and ER regions (indicated by the green circles). Scale bar $=20 \mu \mathrm{m}$.

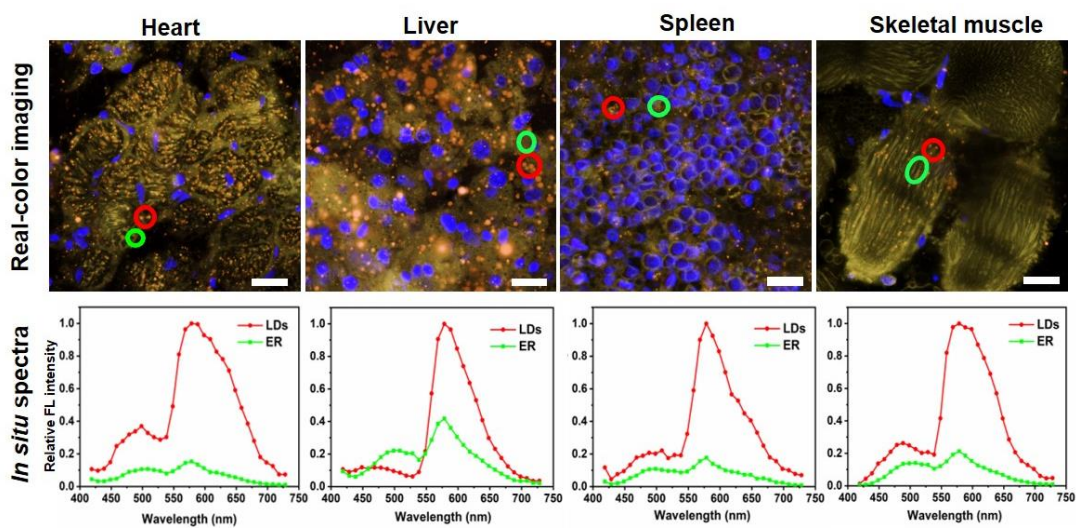

Figure S28. Real-color confocal fluorescent images of EPC merged with the pseudo-color images of SYTO 61 (blue) in various tissues, as well as the corresponding in situ fluorescence spectra in LDs (indicated by the red circles) and ER regions (indicated by the green circles). Scale bar $=20 \mu \mathrm{m}$. 

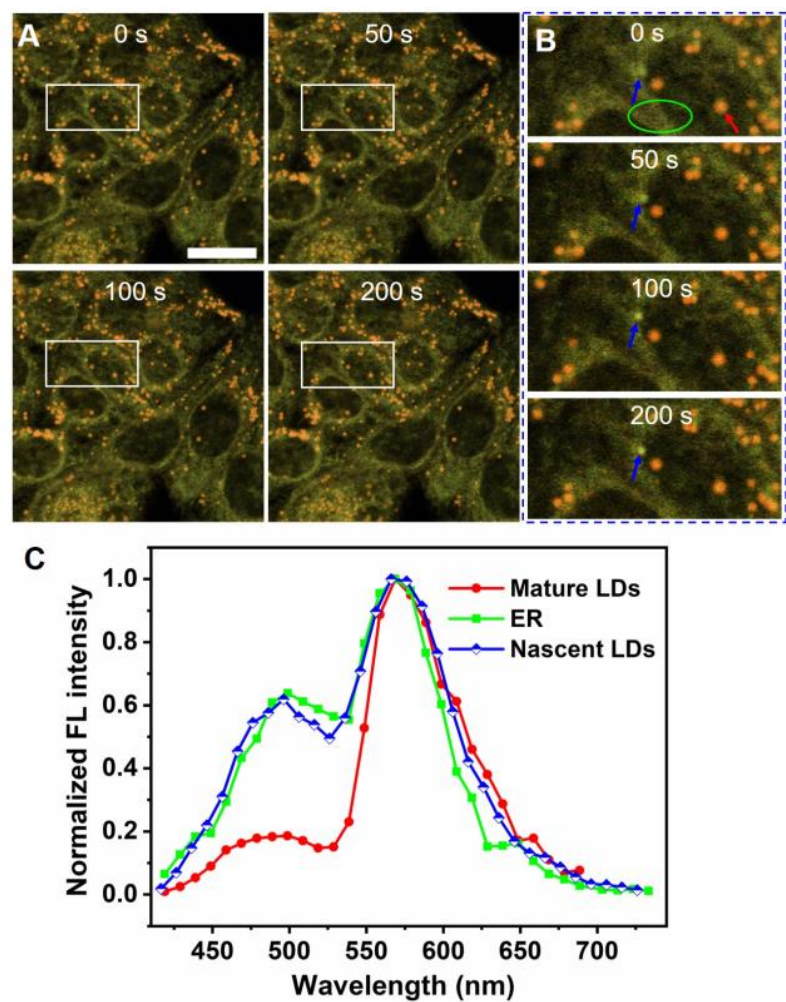

Figure S29. (A) In situ dynamic monitoring of LDs formation in oleic acid pre-treated HeLa cells stained with EPC at different time points. (B) The enlarged fluorescent images of the ROIs indicated by the white rectangle in Figure 8A. (C) In situ fluorescence spectra of mature LDs (indicated by the red arrow), ER (indicated by the green circle), and nascent LDs (indicated by the blue arrow). $\lambda_{\mathrm{ex}}=$ $405 \mathrm{~nm}$. Scale bar $=20 \mu \mathrm{m}$.
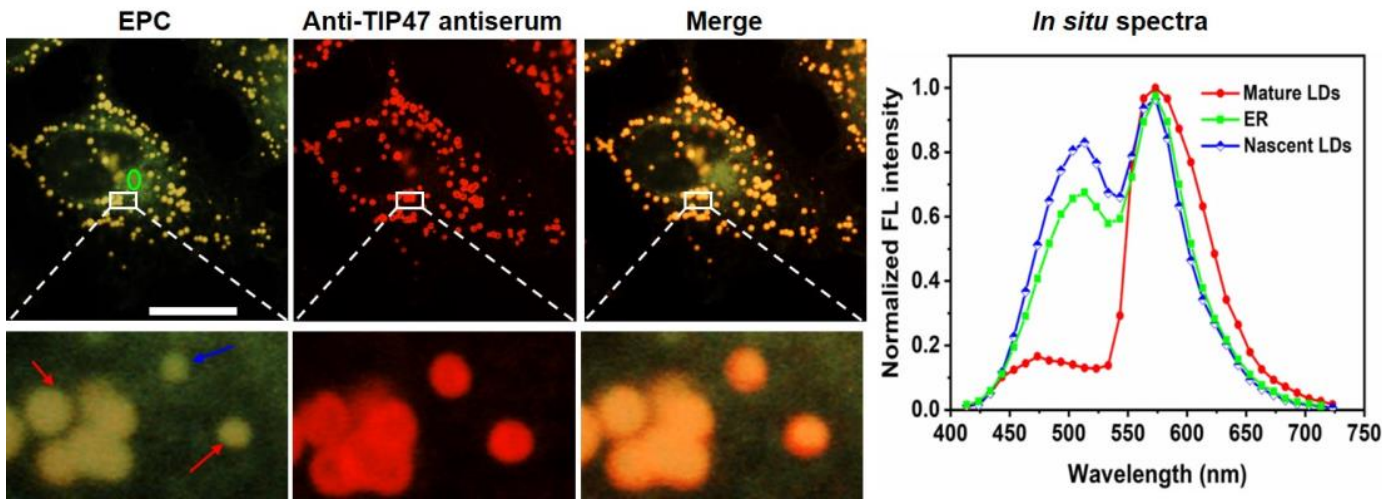

Figure S30. Real-color fluorescent images of oleic acid pre-treated HeLa cells stained with EPC and anti-TIP47 antiserum and the corresponding in situ fluorescence spectra in nascent LDs (indicated by the blue arrows), mature LDs (indicated by the red arrows), and ER (indicated by the green circle). EPC: $\lambda_{\mathrm{ex}}=405 \mathrm{~nm}$; Anti-TIP47 antiserum (fluorescence from Cy3-conjugated goat anti-rabbit IgG): $\lambda_{\mathrm{ex}}=561 \mathrm{~nm}$. Scale bar $=20 \mu \mathrm{m}$. 


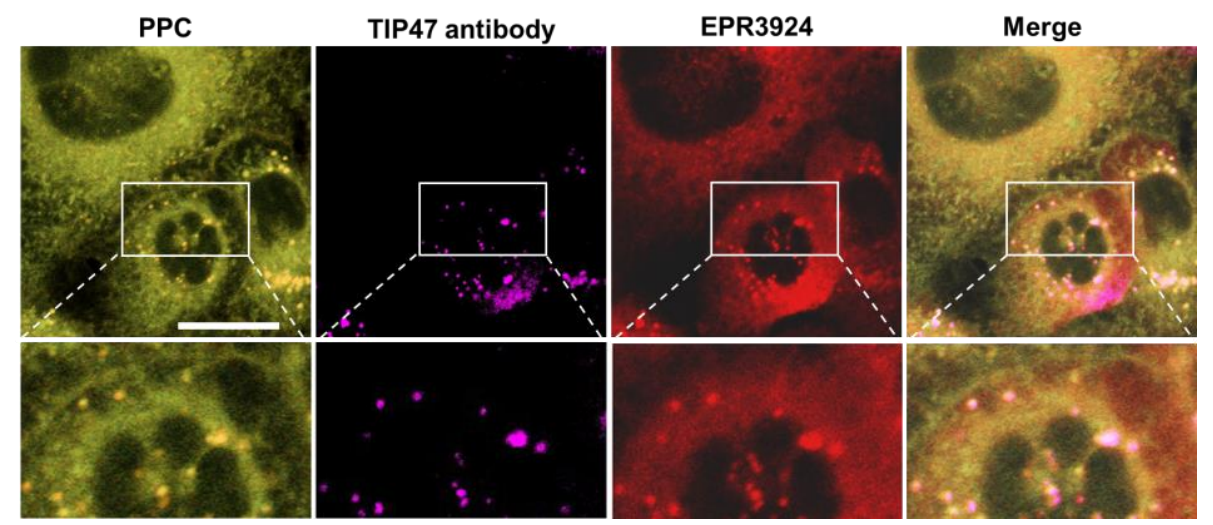

Figure S31. The colocalization experiments between PPC (real-color image) and anti TIP47 (pseudo color image) as well as the ER specific fluorescent immunostaining dye (EPR3924, pseudo color image). PPC: $\lambda_{\text {ex }}=405 \mathrm{~nm}$; TIP47 antibody: $\lambda_{\text {ex }}=561 \mathrm{~nm}$; EPR3914: $\lambda_{\text {ex }}=633 \mathrm{~nm}$. Scale bar $=20$ $\mu \mathrm{m}$. 